\title{
Implications of Representative Concentration Pathway 4.5 Methane Emissions to Stabilize Radiative Forcing
}

W. R. Emanuel

A. C. Janetos Joint Global Change Research Institute

February 2013

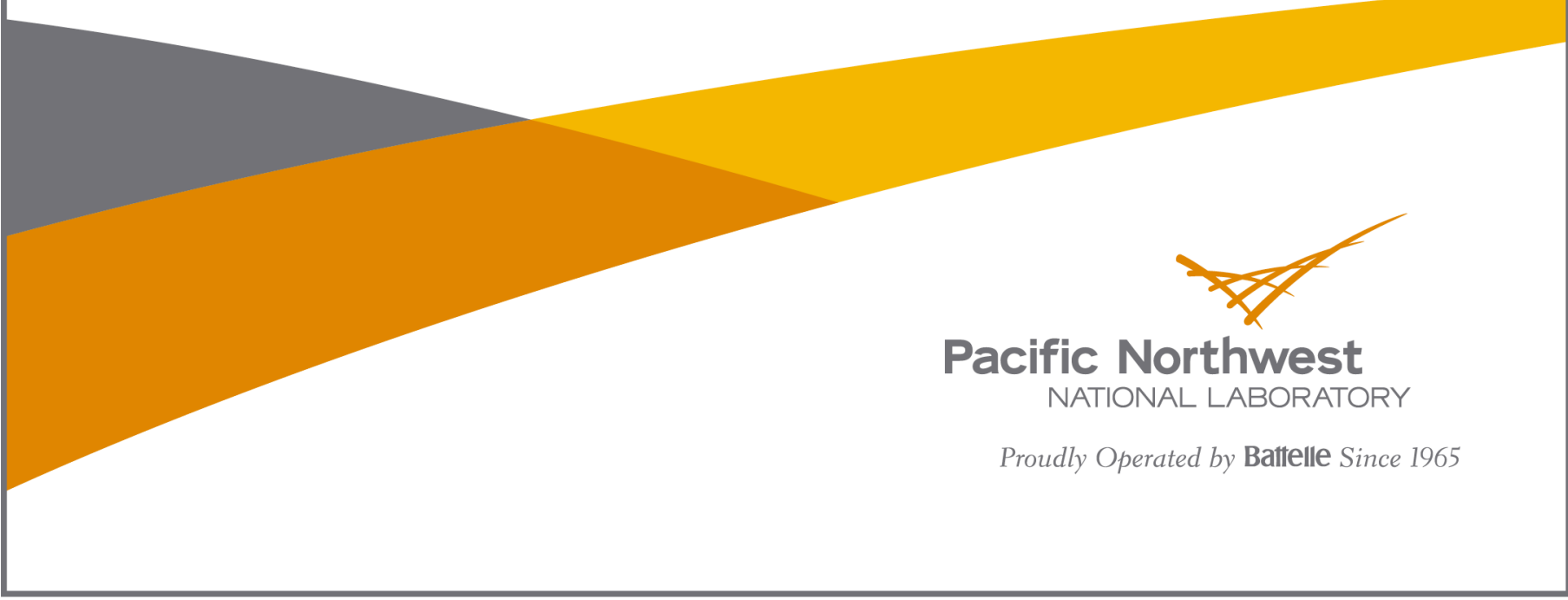


PNNL-22203

\section{DISCLAIMER}

This report was prepared as an account of work sponsored by an agency of the United States Government. Neither the United States Government nor any agency thereof, nor Battelle Memorial Institute, nor any of their employees, makes any warranty, express or implied, or assumes any legal liability or responsibility for the accuracy, completeness, or usefulness of any information, apparatus, product, or process disclosed, or represents that its use would not infringe privately owned rights. Reference herein to any specific commercial product, process, or service by trade name, trademark, manufacturer, or otherwise does not necessarily constitute or imply its endorsement, recommendation, or favoring by the United States Government or any agency thereof, or Battelle Memorial Institute. The views and opinions of authors expressed herein do not necessarily state or reflect those of the United States Government or any agency thereof.

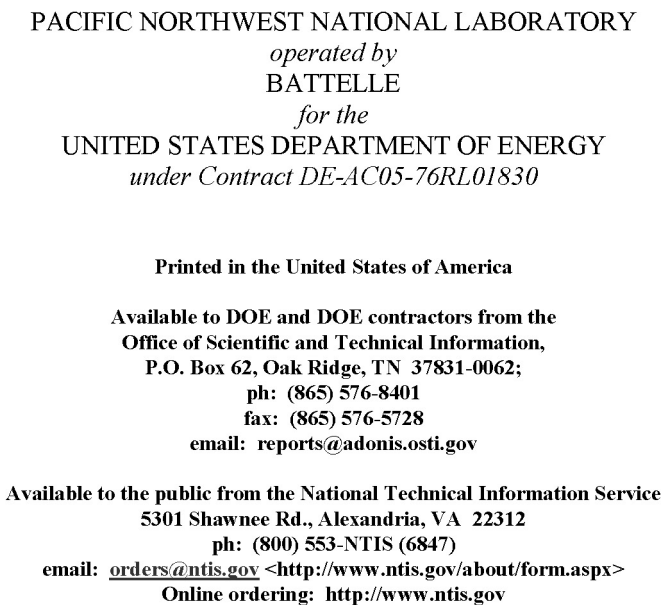

This document was printed on recycled paper.

(8/2010) 


\section{Implications of Representative Concentration Pathway 4.5 Methane Emissions to Stabilize Radiative Forcing}

William R. Emanuel

Anthony C. Janetos

Joint Global Change Research Institute

February 2013

Prepared for

the U.S. Department of Energy

under Contract DE-AC05-76RL01830

Pacific Northwest National Laboratory

Richland, Washington 99352 


\section{Acknowledgements}

The authors gratefully acknowledge guidance and assistance by Allison Thomson and Page Kyle, both of the Joint Global Change Research Institute, regarding assumptions and data underlying the Representative Concentration Pathway 4.5. 


\section{Acronyms and Abbreviations}

$\begin{array}{ll}\mathrm{CCS} & \text { Carbon dioxide capture and storage } \\ \mathrm{CH}_{4} & \text { Methane } \\ \mathrm{CO}_{2} & \text { Carbon dioxide } \\ \mathrm{GCAM} & \text { Global Change Assessment Model } \\ \text { IPCC } & \text { Intergovernmental Panel on Climate Change } \\ \text { JGCRI } & \text { Joint Global Change Research Institute } \\ \text { OECD 90 } & \text { Organization for Economic Cooperation and Development 90 Nations } \\ \mathrm{OH} & \text { Hydroxyl radical } \\ \mathrm{RCP} & \text { Representative Concentration Pathway } \\ \mathrm{UN} & \text { United Nations }\end{array}$




\section{Figures}

Figure 1.1. Historical atmospheric $\mathrm{CH}_{4}$ concentration derived from direct observations and 1 ice core measurements.

Figure 2.1. Radiative forcing specified to define four representative concentration pathways 3 (RCP) for the $5^{\text {th }}$ assessment by the IPCC.

Figure 2.1.1. World population assumed by the GCAM reference and RCP 4.5 scenarios.

Figure 2.2.1. Radiative forcing of climate change corresponding to Representative Concentration Pathway 4.5 and to the GCAM reference scenario.

Figure 3.1. Total $\mathrm{CH}_{4}$ emissions globally in RCP 4.5 and GCAM reference scenarios.

Figure 3.1.1. Reference scenario $\mathrm{CH}_{4}$ emissions associated with each major region defined 6 by the IPCC for representative concentration pathways.

Figure 3.1.2. Relative methane emissions by region in the reference scenario.

Figure 3.1.3. Reference scenario emissions globally associated with sectors of human 8 activity

Figure 3.1.4. Relative global emissions in the reference scenario associated with major 9 sectors of human activity at selected years in the $21^{\text {st }}$ century.

Figure 3.1.5. Reference scenario emissions associated with the six most significant sectors 10 of human activity within major regions and the world.

Figure 3.2.1. Methane emissions associated with major regions projected for the RCP 4.511 scenario.

Figure 3.2.2. Relative distribution of total $\mathrm{CH}_{4}$ emissions under RCP 4.5 by major regions at 12 selected years within the $21^{\text {st }}$ century.

Figure 3.2.3. Global emissions under RCP 4.5 associated with the six most significant 13 sectors of human activity. 
Figures (continued)

Figure 3.2.4. Relative global emissions under RCP4.5 associated with major sectors of 14 human activity at selected years in the $21^{\text {st }}$ century.

Figure 3.2.6. Methane emissions constrained by RCP 4.5 by major region and sector.

Figure 3.3.1. Geographic distribution of total $\mathrm{CH}_{4}$ emissions by human activities in 201017 under the RCP 4.5 scenario based on spatial correlations with underlying factors responsible for or aligned with emissions.

Figure 3.3.2. Sectors of human activity contributing most to methane emissions in 2010.

Figure 4.1. Differences by sectors and regions between reference scenario and RCP $4.5 \quad 19$ emissions.

Figure 5.1. Difference between methane emissions in the reference and RCP 4.5 scenarios 22 by region: (A) absolute difference in emissions; (B) difference in emissions relative to emissions in the reference scenario. 


\section{Tables}

Table 1.1.1. Natural sources of atmospheric methane. 


\section{Contents}

Acknowledgements

Acronyms and Abbreviations $\quad$ ii

Figures $\quad$ iii

Tables $\quad$ V

1. Introduction 1

1.1 Atmospheric Methane Sources and Sinks 1

2. Representative Concentration Pathways 2

2.1 Reference Scenario for Representative Concentration Pathway 4.5 3

2.2 Representative Concentration Pathway 4.5 4

3. Methane Emissions $\quad 5$

3.1 Reference Scenario Emissions $\quad 6$

3.2 Emissions Constrained by Representative Concentration Pathway 4.5 11

3.3 Geospatial Patterns in RCP 4.5 Emissions 16

4. Emissions Mitigation Implied by RCP 4.5 18

5. Discussion and Conclusion $\quad 20$

6. Literature Cited 23

Appendix A - RCP Region Definitions 25 


\section{Implications of Representative Concentration Pathway 4.5 Methane Emissions to Stabilize Radiative Forcing}

\section{Introduction}

Increases in the abundance of methane $\left(\mathrm{CH}_{4}\right)$ in the Earth's atmosphere are responsible for significant radiative forcing of climate change (Forster et al., 2007; Wuebbles and Hayhoe, 2002). Since 1750, a 2.5 fold increase in atmospheric $\mathrm{CH}_{4}$ contributed $0.5 \mathrm{~W} / \mathrm{m}^{2}$ to direct radiative forcing and an additional $0.2 \mathrm{~W} / \mathrm{m}^{2}$ indirectly through changes in atmospheric chemistry. Next to water and carbon dioxide $\left(\mathrm{CO}_{2}\right)$, methane is the most abundant greenhouse gas in the troposphere. Additionally, $\mathrm{CH}_{4}$ is significantly more effective as a greenhouse gas on a per molecule basis than is $\mathrm{CO}_{2}$, and increasing atmospheric $\mathrm{CH}_{4}$ has been second only to $\mathrm{CO}_{2}$ in radiative forcing (Forster et al., 2007).

The chemical reactivity of $\mathrm{CH}_{4}$ is important to both tropospheric and stratospheric chemistry. Along with carbon monoxide, methane helps control the amount of the hydroxyl radical $(\mathrm{OH})$ in the troposphere where oxidation of $\mathrm{CH}_{4}$ by $\mathrm{OH}$ leads to the formation of formaldehyde, carbon monoxide, and ozone.

Figure 1.1 shows historical atmospheric methane concentrations over the past 1,000 years based on direct observations (e.g., Dlugokencky et al., 2011) and icecore measurements (e.g., Etheridge et al., 1998). During the period 1000-1750, the atmospheric concentration of $\mathrm{CH}_{4}$ was on average about $650 \mathrm{ppb}$. The abundance of $\mathrm{CH}_{4}$ increased steadily after 1750 to a global average concentration in 2009 of 1,794 ppb (Dlugokencky et al., 2011; Denman et al., 2007).

\subsection{Atmospheric Methane Sources and Sinks}

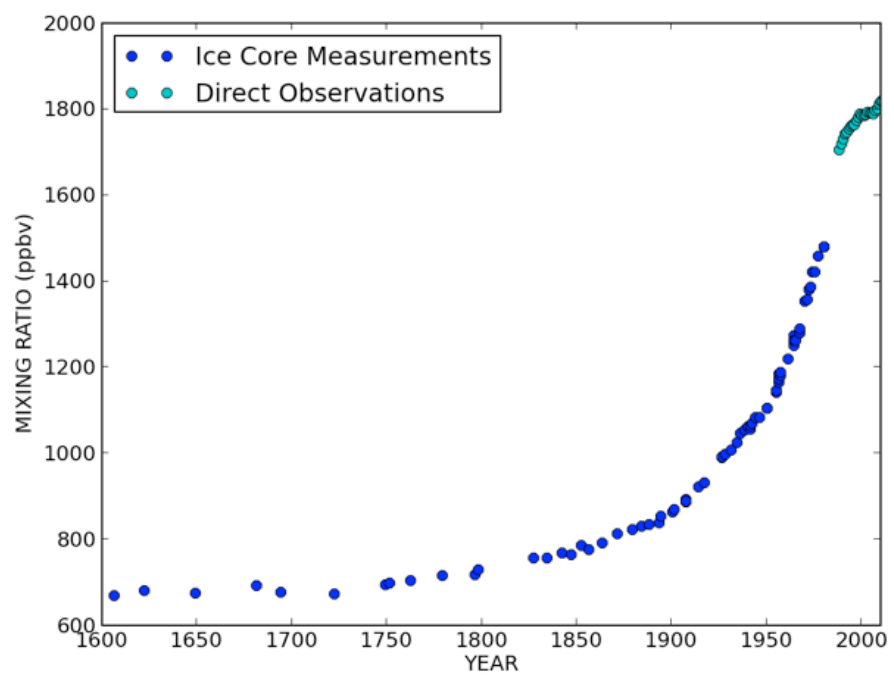

Figure 1.1. Historical atmospheric $\mathrm{CH}_{4}$ concentration derived

Decomposition of organic matter by bacteria in the absence of oxygen is from direct observations and ice core measurements (Etheridge et al., 1998; Dlugokencky et al., 2011).

responsible for the largest source of methane to the atmosphere. Wetlands, including rice paddies, are the most prevalent environment for this process; however, methane is also produced in other water bodies such as submerged sediments, landfills, and waste treatment facilities. Additional natural sources of $\mathrm{CH}_{4}$ occur with fire and certain geologic processes. 
In a report for the U.S. Environmental Protection Agency, Anderson et al. (2010) summarize methane emissions from natural sources (Table 1.1.1).

Table 1.1.1. Natural sources of atmospheric methane

\begin{tabular}{l|l|l}
\hline \multicolumn{1}{c|}{ Source } & \multicolumn{1}{c}{$\begin{array}{c}\text { Emissions } \\
\left(\mathrm{Tg} \mathrm{CH}_{4} / \text { year }\right)\end{array}$} & $\begin{array}{c}\text { Range } \\
(\mathrm{Tg} \mathrm{CH} / \text { year })\end{array}$ \\
\hline Wetlands & 170.3 & \\
$\quad$ Northern bogs & 42.7 & $24-72$ \\
$\quad$ Tropical swamps & \multicolumn{1}{|c|}{127.6} & \multicolumn{1}{c}{$81-206$} \\
Oceans, estuaries, and rivers & 9.1 & $2.3-15.6$ \\
Permafrost & 0.5 & $0-1$ \\
Lakes & 30 & $10-50$ \\
Gas hydrates & & $2-9$ \\
Geologic sources & & $42-64$ \\
Wildfire & & $2-5$ \\
Terrestrial arthropods & 20 & $2-22$ \\
Wild animals & 8 & $2-15$ \\
\hline
\end{tabular}

$\left(1 \mathrm{Tg}=1\right.$ teragram $\left.=1 \times 10^{12}\right)$ Source: Anderson et al. $(2010)$

Methane emissions associated with human activities are difficult to estimate (e.g., Khalil and Rasmussen, 1994). Agriculture, waste management, energy production, and other major sources of $\mathrm{CH}_{4}$ to the atmosphere are widely dispersed and relationships between emissions and the intensity or magnitude of the underlying activity vary with location and practices. For example, $\mathrm{CH}_{4}$ emissions per unit area from rice grown in one region or managed in a specific way can vary substantially from the same crop grown in another region or managed differently. As a result, methane emission estimates are significantly less certain than those for $\mathrm{CO}_{2}$. Scheehle and Kruger (2006) estimate historical emissions by human activities in 1990, 1995, and 2000 based on emissions reports by individual countries.

The major sink for atmospheric $\mathrm{CH}_{4}$ is through its reaction in the troposphere with $\mathrm{OH}$, and the concentration of $\mathrm{OH}$ in the atmosphere is the primary factor determining the rate of $\mathrm{CH}_{4}$ transformation. The average lifetime of $\mathrm{CH}_{4}$ in the atmosphere as a result of this and other minor sinks is approximately 9.1 years (Prather et al., 2012).

\section{Representative Concentration Pathways}

Significant ranges of resource utilization, technological development, and other socioeconomic futures can lead to a particular scenario of radiative forcing, and climate change integrated assessment models are used to derive these resource, technological, and socioeconomic pathways such that future greenhouse gas emissions and changes in atmospheric composition are consistent with a specified pathway of radiative forcing. For its fifth assessment of climate change, the Intergovernmental Panel on Climate Change (IPCC) adopted a new approach to scenarios by specifying four scenarios of future radiative forcing of climate change instead of deriving these through a scenario development process beginning with assumptions about the 
factors that affect greenhouse gas emissions (Moss et al., 2010). The IPCC refers to a projection of atmospheric concentrations corresponding to a particular pathway of radiative forcing as a representative concentration pathway (RCP) (van Vuuren et al., 2011).

Each of the RCPs specifies radiative forcing and the associated concentrations of the atmospheric constituents involved over the period 1850-2100. The set of four RCPs adopted by the IPCC lead to globally averaged radiative forcing at year 2100 of 8.5, 6.0, 4.5, and $2.6 \mathrm{~W} / \mathrm{m}^{2}$ (Fig. 2.1). At the time they were developed, the RCPs represented the full range of emissions scenarios described in the relevant literature, with and without climate policies. While scenarios described by the IPCC Special Report on Emission Scenarios (Nakicenovic et al., 2000) are consistent with assumptions about future human activities in the absence of specific mitigation efforts or other climate relevant policies. Realizations of

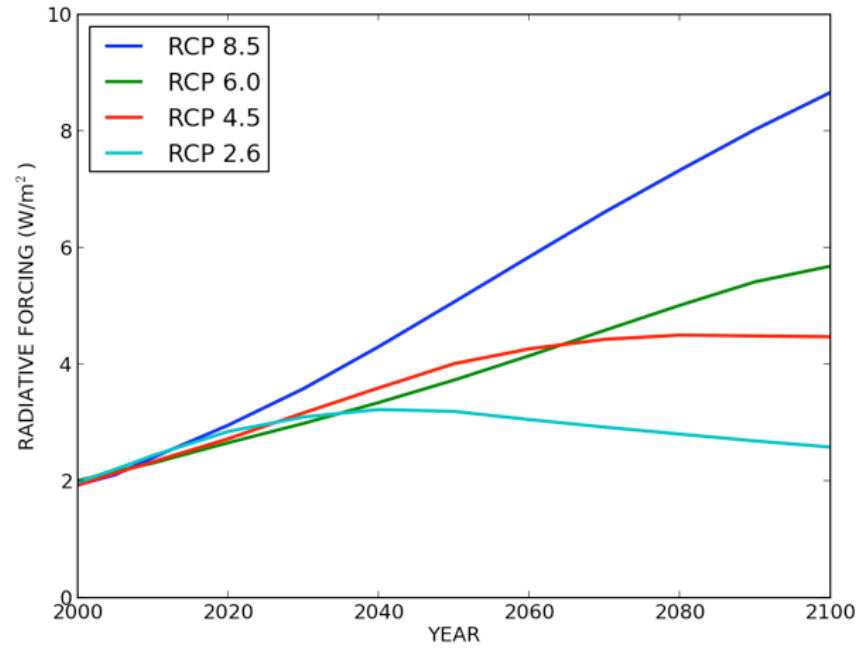

Figure 2.1. Radiative forcing specified to define four representative concentration pathways for the $5^{\text {th }}$ assessment by the IPCC (van Vuuren et al., 2011). these representative concentration pathways require varying degrees of mitigation to slow or reduce rates of greenhouse gas emissions from associated reference scenarios that are not constrained by climate relevant management or policies.

\subsection{Reference Scenario for Representative Concentration Pathway 4.5}

In order to derive scenario attributes that satisfy a radiative forcing constraint, the representative concentration pathways incorporate options with respect to a reference scenario (van Vuuren et al., 2011). The $4.5 \mathrm{~W} / \mathrm{m}^{2} \mathrm{RCP}$ is based on a reference scenario described by Clarke et al. (2007), updated to incorporate information on greenhouse gas emissions other than $\mathrm{CO}_{2}$ summarized by Smith and Wigley (2006) and on land use and terrestrial carbon emissions pricing described by Wise et al. (2009).

Referred to as the GCAM reference scenario, this scenario assumes that no policies exist regarding climate change,

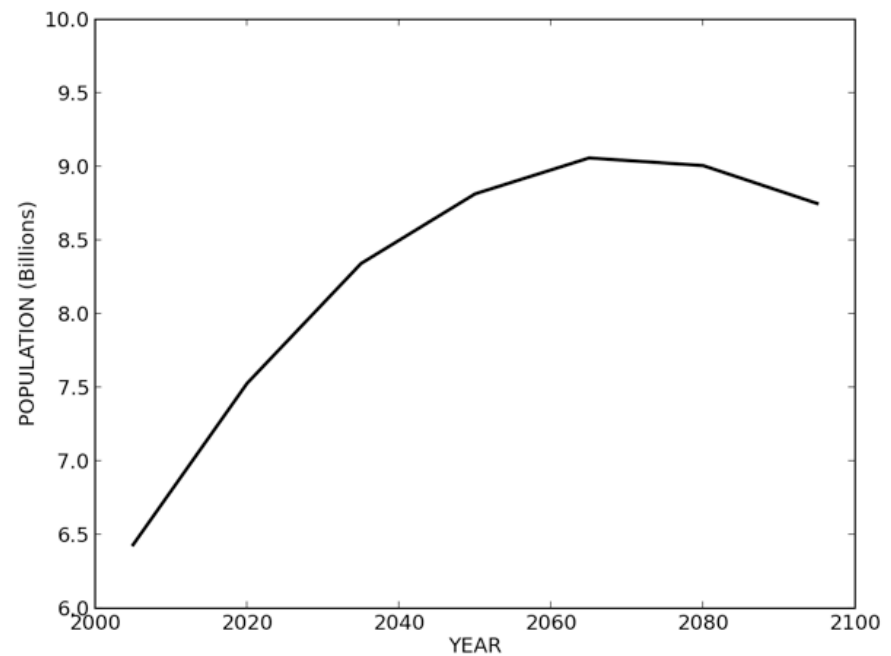

Figure 2.1.1. World population assumed by the GCAM reference and RCP 4.5 scenarios. The population projection is based on UN (2006) and O'Neill (2005). and thus, policies do not limit greenhouse gas emissions or radiative forcing. The reference scenario is based on a median United Nations population projection (UN, 2006) and population scenarios described by O'Neill (2005) (Fig. 
2.2.1). Population increases substantially during the $21^{\text {st }}$ century to a maximum in year 2065 of 9 billion people; however, by year 2100 , the rate of increase slows to near zero at a population of about 8.6 billion.

Global primary energy use expands from $400 \mathrm{EJ} /$ year in 2000 to 1,250 EJ/year in $2100(1 \mathrm{EJ}=1$ Exajoule $=1 \times 10^{18}$ joules), and per capita energy consumption grows with rising economic activity, increasing efficiency of energy use, and changes in patterns of energy consumption. Under the GCAM reference scenario, fossil fuels provide most of the world's energy, comprising $90 \%$ of energy resources in year 2000 and remaining the dominant source throughout the century. Reliance on natural gas and coal increases. Electricity production increases steadily through the century, and coal continues to be a significant resource, accounting for more than half of all power production at the end of the century. Natural gas is assumed to be relatively abundant and provides a significant energy resource.

\subsection{Representative Concentration Pathway 4.5}

The representative concentration pathway to radiative forcing of $4.5 \mathrm{~W} / \mathrm{m}^{2}$ (RCP 4.5) (Fig. 2.2.1) corresponds to significant, but likely realizable, mitigation of greenhouse gas emissions and related factors (Peters $e t$ al., 2013; Thomson et al., 2011). In this regard, RCP 4.5 provides a useful scenario for analyzing actions to reduce climate change and its impacts from those expected under "business-as-usual."

The RCP 4.5 scenario assumes that globally, prices imposed on greenhouse gas emissions limit emissions so as to stabilize radiative forcing at $4.5 \mathrm{~W} / \mathrm{m}^{2}$ by 2100 (Thomson et al., 2011). The scenario was derived using the Global Change Assessment Model (GCAM) developed and maintained by the Joint Global Change Research Institute of the Pacific Northwest National Laboratory

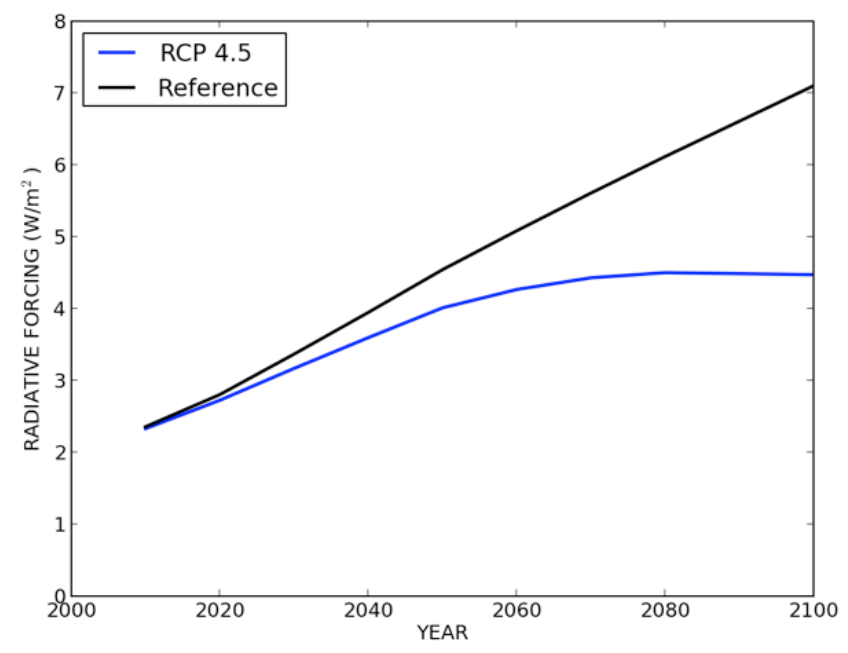

Figure 2.2.1. Radiative forcing of climate change corresponding to Representative Concentration Pathway 4.5 and to the GCAM reference scenario. Under the RCP 4.5 scenario, radiative forcing increases to approximately 4.5 $\mathrm{W} / \mathrm{m}^{2}$ by year 2100 without rising above that level. and the University of Maryland. Within GCAM simulations, all nations are assumed to undertake emissions mitigation simultaneously and effectively, sharing a common global price on all emissions into the atmosphere. The emissions of different gases are priced according to their 100 year global warming potentials (Forster et al., 2007).

As in the reference scenario, RCP 4.5 assumes that global population increases to a maximum of 9 billion people in 2065 and then declines to 8.7 billion people in 2100 (Fig. 2.1.1). Gross domestic product increases by a factor of 10 , and global primary energy consumption triples. In order to stabilize radiative forcing at $4.5 \mathrm{~W} / \mathrm{m}^{2}$ by 2100 , overall energy use as well as fossil fuel use decrease compared to the reference case. The use of renewable energy sources and of nuclear 
energy increases substantially under RCP 4.5. Electricity meets a larger portion of end-use energy demands.

Large-scale carbon dioxide capture and storage (CCS) allows continued use of fossil fuels while meeting the RCP 4.5 stabilization constraint, although total fossil fuel use decreases through time. Additionally, bioenergy sources used in conjunction with CCS are assumed to enable net removal of $\mathrm{CO}_{2}$ from the atmosphere. Carbon dioxide capture from emissions by combustion of biofuels and long-term storage represents one of very few potential options for reducing atmospheric $\mathrm{CO}_{2}$ rather than simply by decreasing emissions. Carbon from the atmosphere accumulating in growing plants that are used to produce a biofuel, once captured from emissions and stored, constitutes net removal of $\mathrm{CO}_{2}$ for as long as storage continues, providing the standing stock of plants is also sustained.

In the RCP 4.5 scenario, forests expand to offset other emissions, and the associated land use competes with bioenergy production by assuming that all carbon associated with fossil fuel and land use emissions are charged an equal penalty price such that reducing land use emissions mitigates global emissions (Wise et al., 2009). Even with expansion of forest cover, bioenergy remains a significant energy source in 2100 . This occurs in part by shifting people's diet toward food associated with less carbon emissions, principally by reducing beef consumption. This shift from beef also reduces methane emissions (Thomson et al., 2010).

\section{Methane Emissions}

Globally, total preindustrial $\mathrm{CH}_{4}$ emissions due to both human activities and natural processes were about 200-250 $\mathrm{Tg}$ $\left(\mathrm{CH}_{4}\right)$ /year. Of these total emissions, natural processes were responsible for approximately 190-220 $\mathrm{Tg}\left(\mathrm{CH}_{4}\right)$ /year, and the remainder was associated with human activities. By contrast, sources associated with human activities now account for more than $60 \%$ of total emissions (Denman et al., 2007).

In the GCAM reference scenario for RCP $4.5, \mathrm{CH}_{4}$ emissions increase from $310 \mathrm{Tg}$ $\left(\mathrm{CH}_{4}\right) /$ year in 2010 to $450 \mathrm{Tg}\left(\mathrm{CH}_{4}\right) /$ year in year 2100 (Fig. 3.1). Under the constraint of RCP 4.5, emissions of $\mathrm{CH}_{4}$ increase from $310 \mathrm{Tg}\left(\mathrm{CH}_{4}\right) /$ year in 2010 to a maximum of $334 \mathrm{Tg}\left(\mathrm{CH}_{4}\right) /$ year in 2040 and then decline steadily through the remainder of the

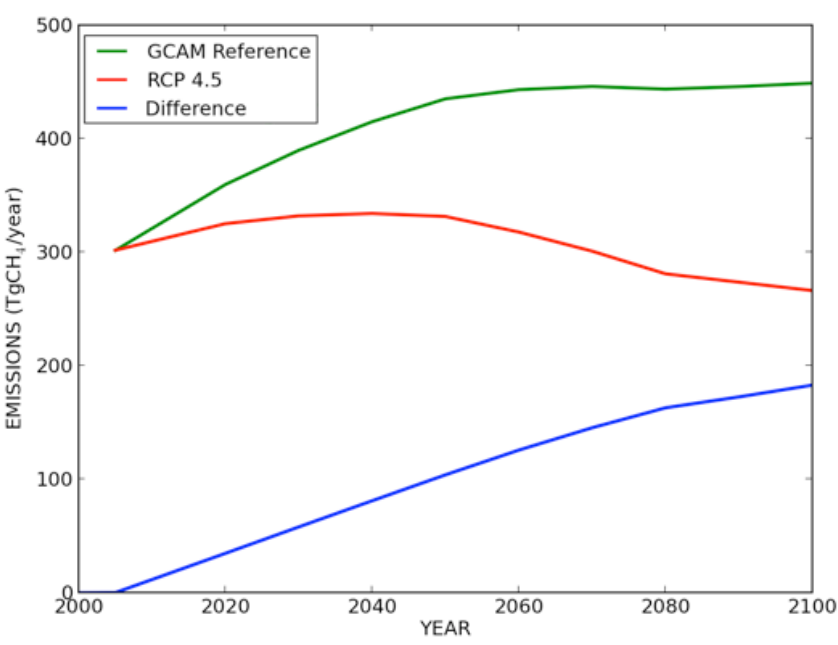

Figure 3.1. Total $\mathrm{CH}_{4}$ emissions globally in RCP 4.5 and the GCAM reference scenario. The difference between emissions for these two scenarios indicates the net emissions that must be avoided annually or offset by sinks in order to realize the lower RCP 4.5 instead of reference scenario emissions. century to $266 \mathrm{Tg}\left(\mathrm{CH}_{4}\right)$ /year in year 2100 for a net decrease from 2010 emissions of about $12 \%$.

The difference between emissions within these two scenarios (blue line in Fig. 3.1) indicates the amount of $\mathrm{CH}_{4}$ emissions each year that must be avoided or offset in order to realize the lower 
RCP 4.5 emissions pathway instead higher emissions in the GCAM reference scenario. By year $2100,40 \%$ of emissions under the GCAM reference scenario must be mitigated in order to realize RCP 4.5 emissions of only about $266 \mathrm{Tg}\left(\mathrm{CH}_{4}\right)$ /year.

Thus, methane emissions under RCP 4.5 represent substantial mitigation with respect to past trends and the reference scenario. Between 1950 and 2000, emissions increased from approximately 184 to $300 \mathrm{Tg}\left(\mathrm{CH}_{4}\right)$ /year, an increase of almost 40\%. By comparison, emissions in 2100 under RCP 4.5 are $41 \%$ less than year 2100 reference scenario emissions. Holding the maximum increase in emissions over the next 30 years to about $10 \%$ and then decreasing emissions from current levels by about $12 \%$ corresponds to a significant departure from past trends and from the reference scenario.

\subsection{Reference Scenario Emissions}

The IPCC representative concentration pathways organize nations into five regional groups: Organization for Economic Cooperation and Development 90 (OECD 90), nations from the region of reforming economies, Asia, the Middle East and Africa, and Latin America (Appendix A). Figure 3.1.1 displays reference scenario emissions for each of these major regions.

Human activities within the Asian countries are responsible for the largest fraction of total emissions, increasing to a maximum value by about 2060 then declining somewhat. The largest increase in regional emissions is by countries in the Middle East and Africa from $44 \mathrm{Tg}\left(\mathrm{CH}_{4}\right) /$ year in 2010 to $117 \mathrm{Tg}\left(\mathrm{CH}_{4}\right) /$ year in 2100. Emissions by countries in the region of reforming economies increase to a maximum in year

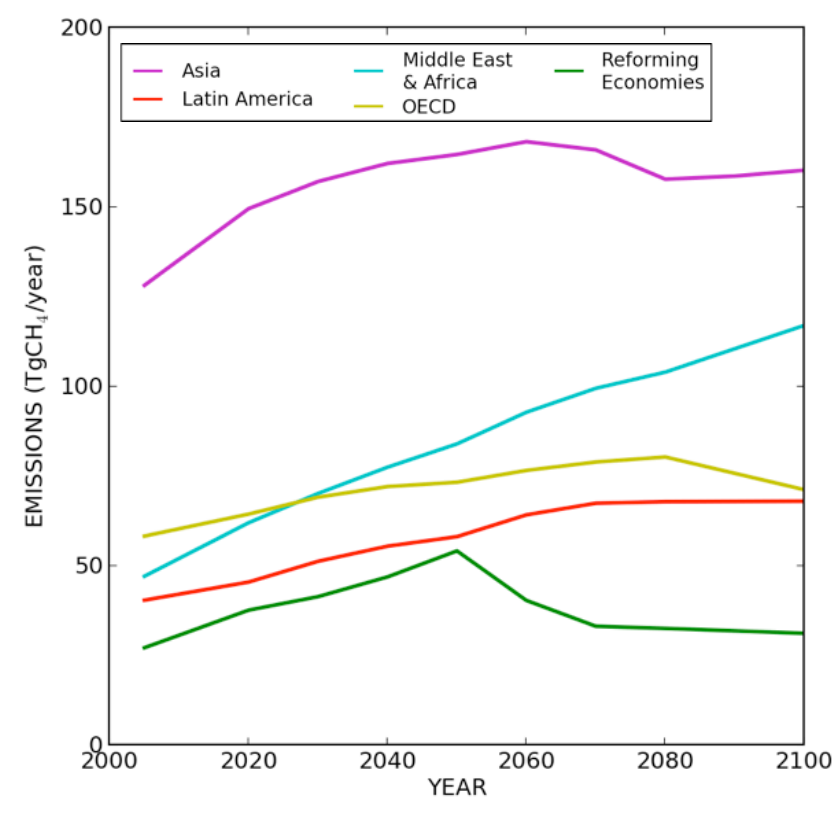

Figure 3.1.1. Reference scenario $\mathrm{CH}_{4}$ emissions associated with each major region defined by the IPCC for representative concentration pathways. 2050 then decrease significantly to a level in 2100 approximately equal to emissions in 2010 .

Throughout the $21^{\text {st }}$ century, total reference scenario emissions associated with each region represents their shares of steadily increasing global emissions (Fig. 3.1.2). Substantial increases in emissions by countries in the Middle East and Africa imply a 10\% increase in their share of global emissions from $16.2 \%$ in 2010 to $26.1 \%$ in year 2100 . Although emissions by Asian countries are significantly larger than those of any other region, the rate of increase in Asian emissions is significantly less than that of countries in the Middle East and Africa, and thus, the relative contribution of Asian emissions to global emissions declines through the century. 

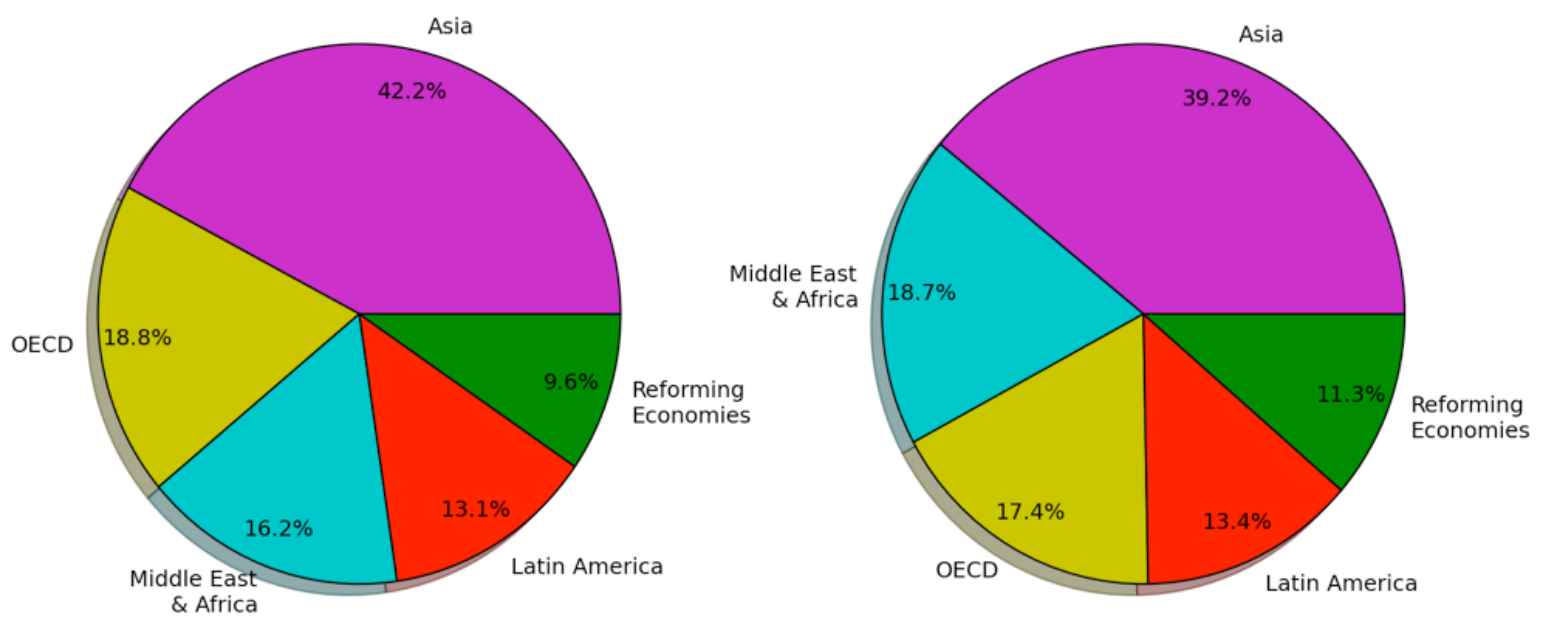

2060
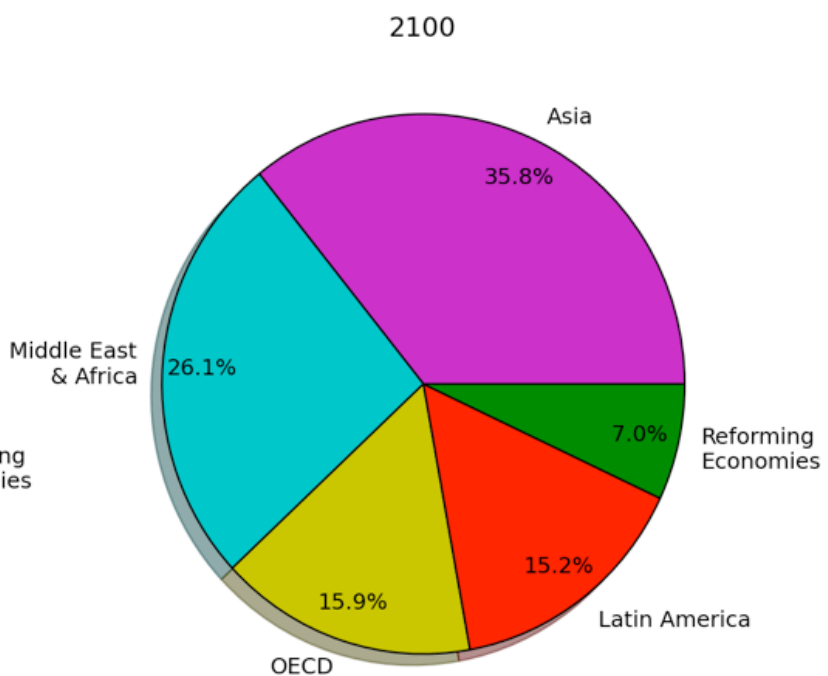

Figure 3.1.2. Relative methane emissions by region in the reference scenario.

The representative concentration pathways associate greenhouse gas emissions with 11 sectors of human activity that are responsible for those emissions:

- Agriculture including animal husbandry, rice production, and emissions from agricultural soils;

- Energy extraction, production, and distribution especially by releasing natural gas and emissions from mining and power plants;

- Waste from landfills and through waste-water processing and incineration of waste for other than energy production;

- Residential and Commercial use of biomass for heating and processes;

- Forest Fire particularly for land use change from forest to other cover types;

- Grassland Fire especially on tropical and subtropical savannahs and for management; 
- Agricultural Waste by burning on fields;

- Solvent production and use;

-Aviation;

- Surface Transportation; and

- Shipping.

Globally, most $\mathrm{CH}_{4}$ emissions in the reference scenario are due to agricultural activities (Fig. 3.1.3). But agricultural emissions stabilize by about 2060 .
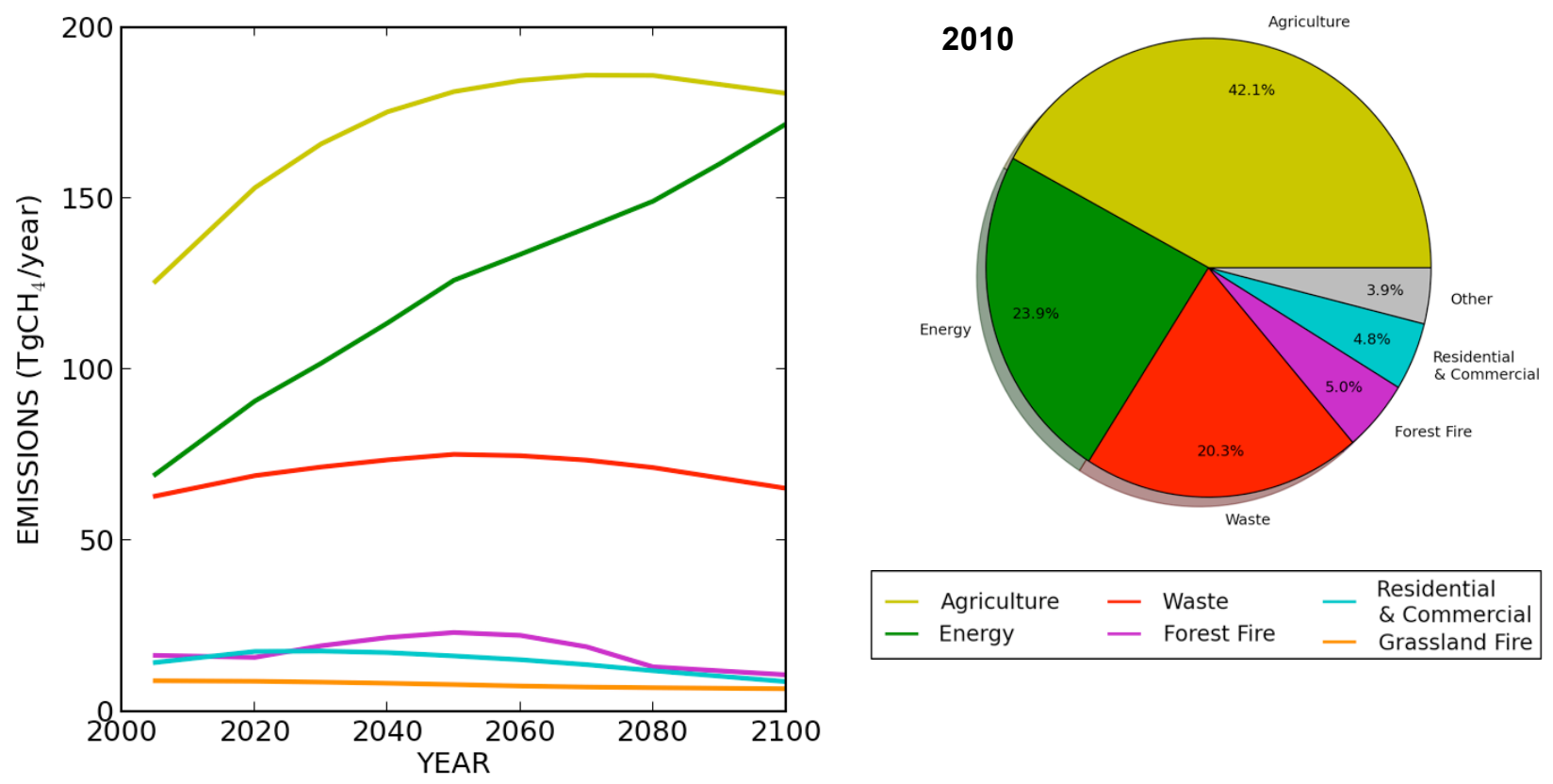

Figure 3.1.3. Reference scenario emissions globally associated with sectors of human activity.

Emissions associated with energy production and use are the second largest contributor to global emissions and increase steadily throughout the $21^{\text {st }}$ century. In 2010 , emissions associated with waste processing and storage are nearly as large as those by the energy sector; however, emissions by the waste sector are nearly constant throughout the century. 
The fraction of total reference scenario emissions by agricultural activities increases through the century from $43 \%$ in 2010 to about $51 \%$ in year 2100 (Fig. 3.1.4). While the increase in emissions by the energy sector is most pronounced, the sector's contribution to total emissions is almost constant through 2060 and then decreases slightly as the increase in emissions by agriculture slows.
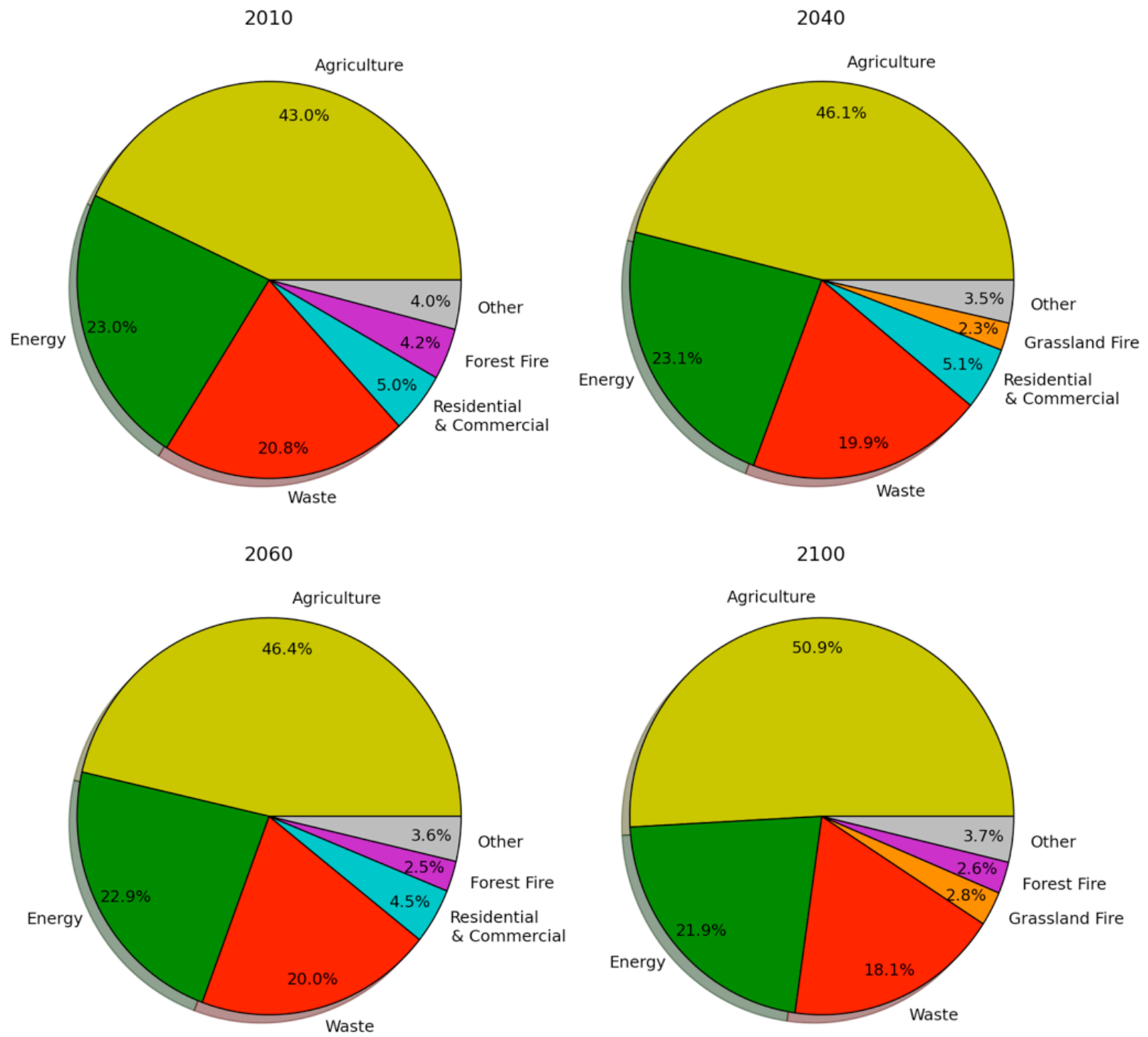

Figure 3.1.4. Relative global emissions in the reference scenario associated with major sectors of human activity at selected years in the $21^{\text {st }}$ century.

Since emissions associated with waste processing and storage are almost constant through the century, the share of this sector in total emissions diminishes somewhat from about $21 \%$ in 2010 to $18 \%$ in year 2100 . The contribution of biofuel use to heat buildings in the residential and commercial sector decreases through the century and becomes less significant than forest and grassland fires by year 2100 . 

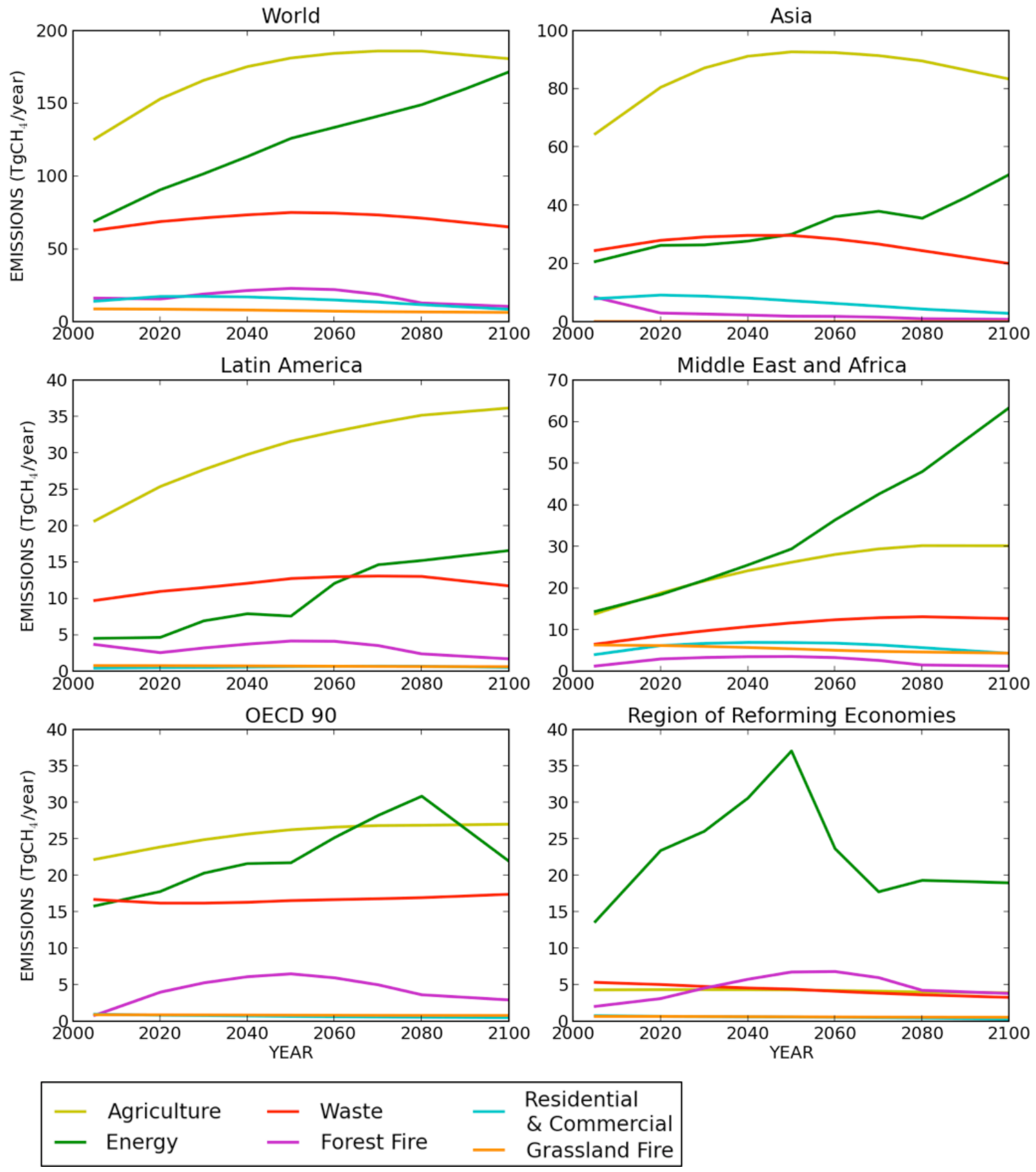

Figure 3.1.5. Reference scenario emissions associated with the six most significant sectors of human activity within major regions and the world. Note that emissions axes are scaled independently for each region.

Trends in reference scenario emissions by sector over the $21^{\text {st }}$ century vary significantly between regions (Fig. 3.1.5). Asian countries are responsible for most of the global trend in agricultural emissions; the steady increase in agricultural emissions by Latin American countries compensates for the mild decrease in Asian emissions after about 2060. 
Although agriculture is responsible for the largest share of global emissions as well as emissions by Asian and Latin American countries, trends in reference scenario emissions by energy production and use underlie the steady increase in total emissions. Prior to 2050, energy sector emissions increase in all regions. Increases in the growth rate of energy emissions by countries of the OECD 90, the Middle East, Africa, and Latin America compensate for the sharp decrease in emissions by countries in the region of reforming economies between 2050 and 2075. Similarly, an increase in the growth rate of Asian emissions beginning in 2080 compensates in part for the decrease in emissions by OECD 90 countries following 2080.

\subsection{Emissions Constrained by Representative Concentration Pathway 4.5}

While in the reference scenario, methane emissions associated with a particular region or sector of human activity tend to increase through time, $21^{\text {st }}$ century emissions constrained by RCP 4.5 tend to stabilize at some point or decrease through time. By definition, RCP 4.5 and reference scenario emissions are the same in 2010, but trends in emissions deviate substantially from that point to year 2100. Figure 3.2.1 displays emissions associated with the major regions defined for scenarios by the IPCC for RCP 4.5 as well as for its reference scenario.

As in the reference scenario, Asian countries contribute to the largest share of total, global emissions. Emissions by Asian countries increase to a maximum in 2040 then decline steadily through the rest of the century to a level in 2100 about $13 \%$ less

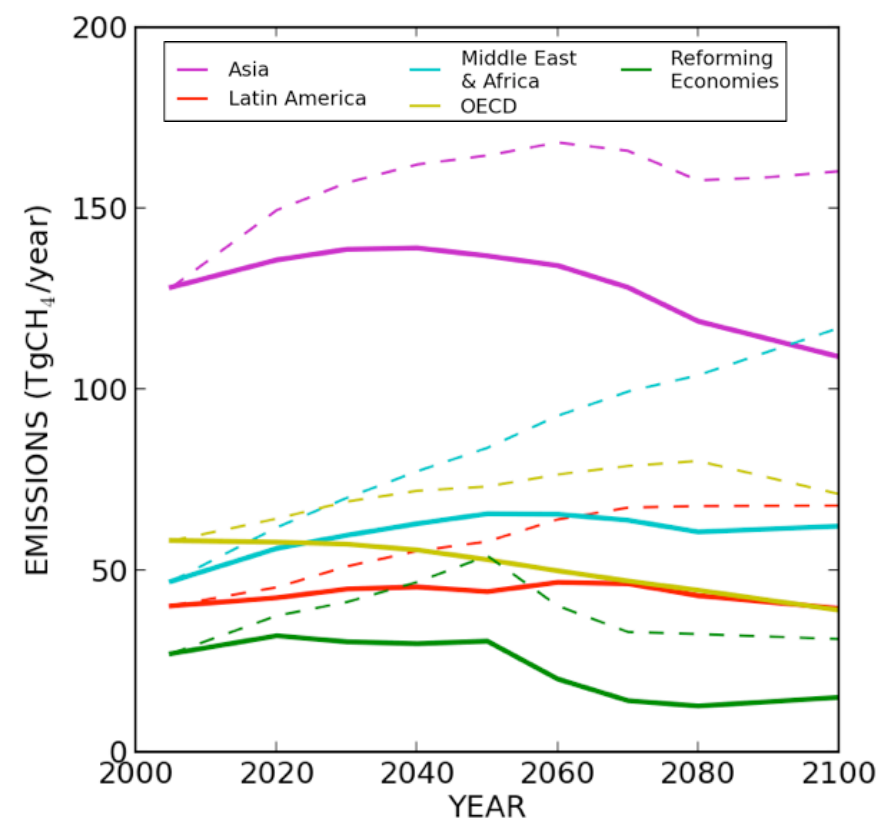

Figure 3.2.1. Methane emissions associated with major regions projected for the RCP 4.5 scenario. Dashed lines display corresponding emissions in the reference scenario. than emissions in 2010. Emissions by countries in the Middle East and Africa increase to a maximum level in 2040 and then stabilize, while projected emissions from Latin American countries remain near constant throughout the century, and those by OECD 90 countries and by countries in the region of reforming economies decrease significantly. The occurrence of a peak in total emissions globally (Figure 3.1) is associated with increases in emissions by Asian countries and by countries in the Middle East and Africa during the first half of the century followed by the downturn in Asian emissions and decreases in emissions by OECD 90 countries and by countries in the region of reforming economies during the second half of the century. 
Although emissions by Asian countries decrease significantly after 2040, because total emissions decrease as well, the Asian contribution to total emissions remains nearly constant throughout the century at about $42 \%$ (Fig. 3.2.2). In turn, emissions by countries of the Middle East and Africa account for an increasing share of total emissions from approximately $16 \%$ in 2010 to $23.5 \%$ in year 2100 . The share of total emissions by the OECD 90 countries and by countries of the region of reforming economies decreases through the century.
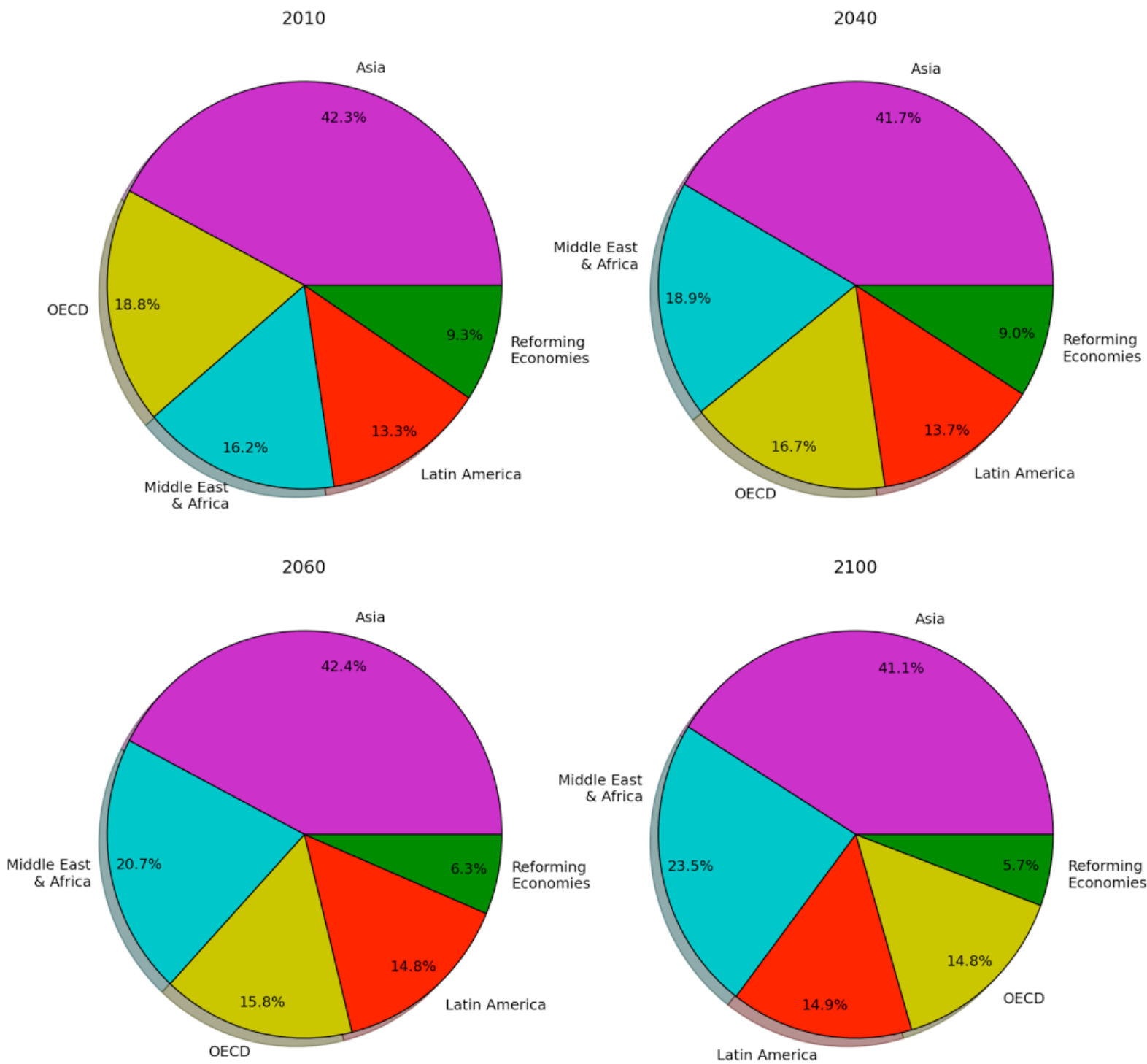

Figure 3.2.2. Relative distribution of total $\mathrm{CH}_{4}$ emissions under RCP 4.5 by major regions at selected years within the $21^{\text {st }}$ century.

Currently, the OECD 90 countries are the second largest contributor to $\mathrm{CH}_{4}$ emissions, comprising about $19 \%$ of total emissions (Fig. 3.2.2). Under the RCP 4.5 scenario, emissions by OECD 90 countries decrease steadily by approximately 36\% from $61 \mathrm{Tg}\left(\mathrm{CH}_{4}\right) /$ year in 2010 to 
$39 \mathrm{Tg}\left(\mathrm{CH}_{4}\right)$ /year in 2100. Emissions by countries with reforming economies also decrease, but not significantly until mid-century, after which emissions decline by approximately $50 \%$ by 2100 .

Methane emissions by countries of the Middle East and Africa rise throughout the century while emissions from Latin American countries are relatively constant. Thus, the peak in total, global emissions in about 2040 is associated with the downturn of emissions associated with Asia, the OCED 90, and countries in the region of reforming economies. The increase in emissions from the Middle East and Africa approximately offsets the decrease associated with the OECD 90 countries.

Figure 3.2.3 summarizes $\mathrm{CH}_{4}$ emissions by the six sectors of human activity responsible for more than $95 \%$ of total emissions in 2010: agriculture (43\%), energy $(23 \%)$, waste handling $(21 \%)$, residential and commercial buildings $(5 \%)$, forest fire for land use change (4\%), and grassland and savannah fire (2\%). Agriculture, energy, and waste processing are the largest contributors, accounting for approximately $87 \%$ of total emissions in 2010. Agriculture alone accounts for about $43 \%$ of total emissions. The increase in emissions by agricultural activities is responsible for most of the increase in total emissions to their maximum in 2040-emissions associated with other sectors are relatively constant by comparison. Decreasing emissions by agriculture, energy production and use, and waste processing and storage are responsible for the steady decline in emissions after 2040; emissions from heating residential and commercial buildings follow a similar
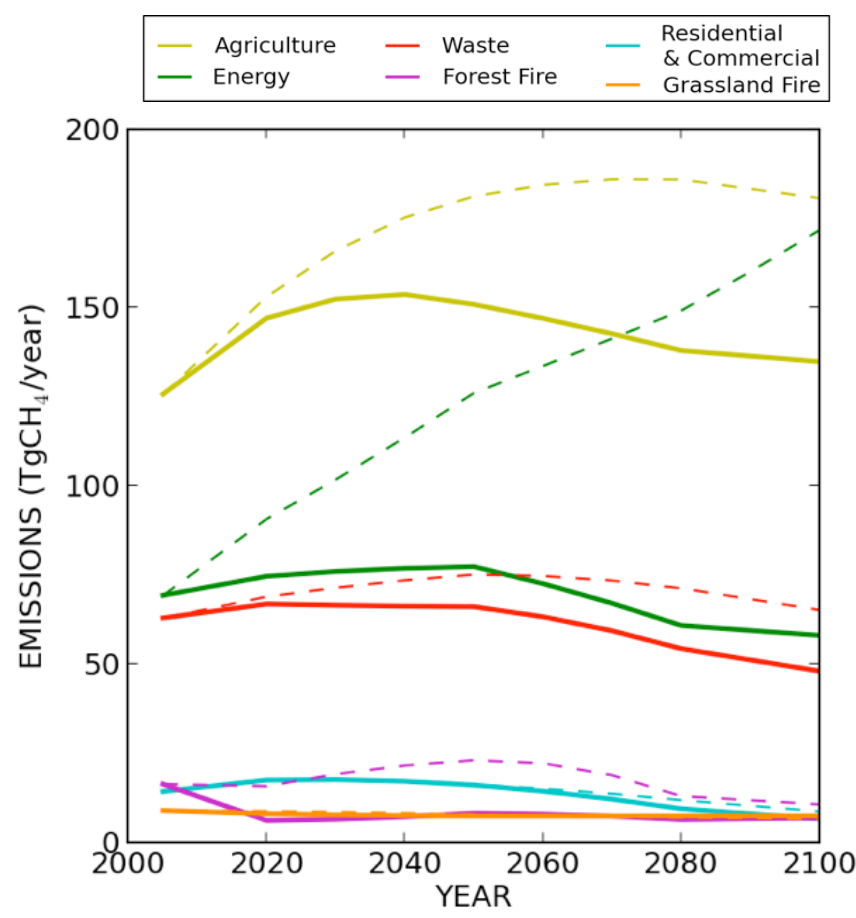

Figure 3.2.3. Global emissions under RCP 4.5 associated with the six most significant sectors of human activity. Dashed lines display corresponding emissions in the reference scenario. course but at substantially lower levels.

The RCP 4.5 scenario assumes that forests are managed to sequester carbon from the atmosphere, and as a consequence, methane emissions by forest fire decline significantly by year 2020. The extent of forest cover also declines as more land is used for food and biofuel production (Thomson et al., 2010). Emissions by grassland fires are nearly constant through the century.

Agriculture is responsible for an increasing share of global emissions through the $21^{\text {st }}$ century, from $43 \%$ in 2010 to near $51 \%$ in 2100 . The fraction of total emissions associated with energy production and use declines somewhat from $23 \%$ in 2010 to about $22 \%$ in 2100 . The significance of global emissions from heating residential and commercial buildings and related processes is significantly less by year 2100. By the end of the century, forest and grassland fire are the 
primary sources of emissions due to biomass burning that is not considered within the energy production and use sector.
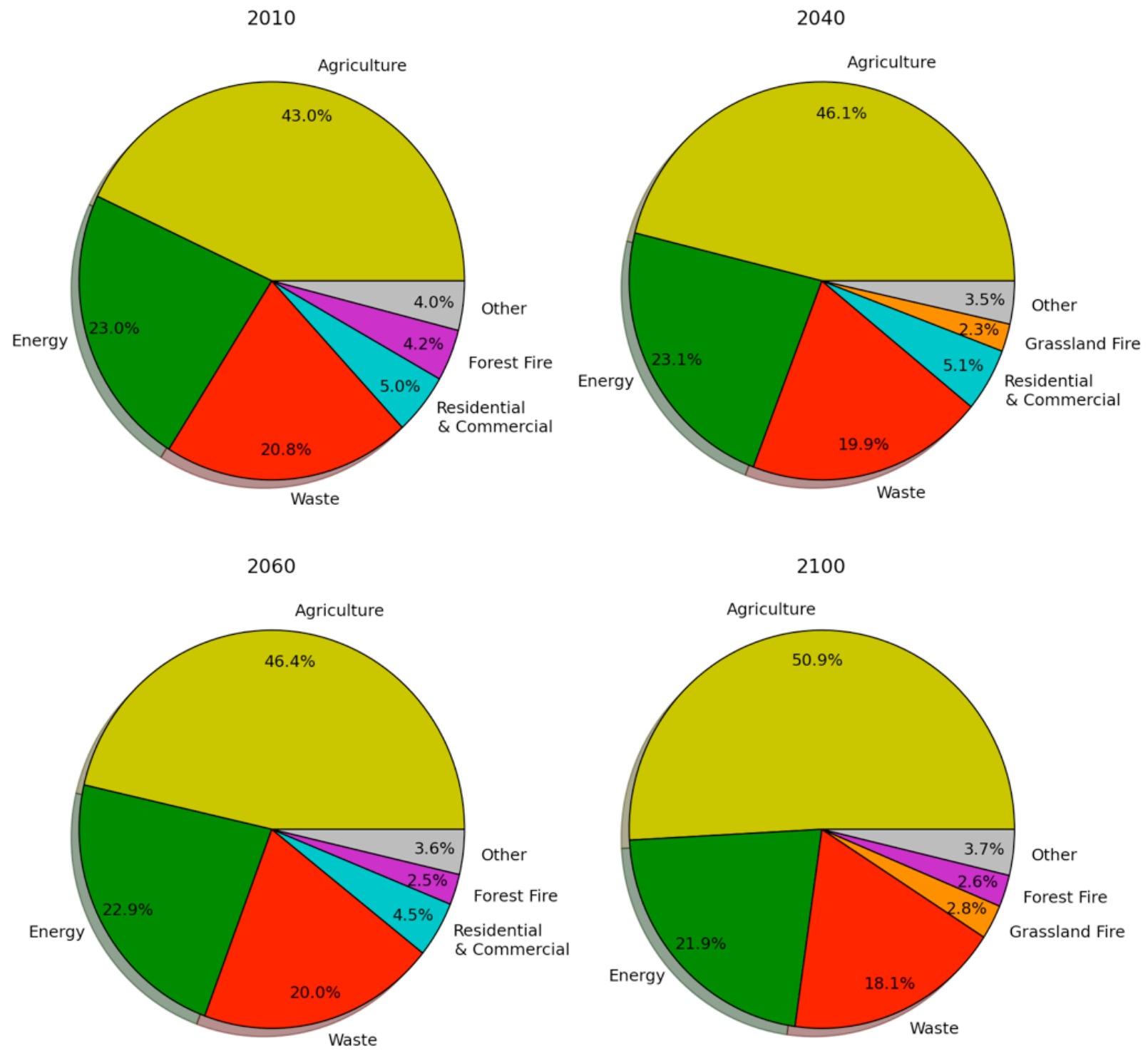

Figure 3.2.4. Relative global emissions under RCP4.5 associated with major sectors of human activity at selected years in the $21^{\text {st }}$ century.

Figure 3.2.4 summarizes the relative contributions to total $\mathrm{CH}_{4}$ emissions by the most significant sectors. The share of emissions by agriculture increases through the century from $43 \%$ in 2010 to over $51 \%$ in 2100 . The relative contribution by energy production and use remains nearly constant through 2060 at about $23 \%$ and then declines somewhat by 2100 . Emissions associated with waste processing and storage follow a similar pattern through time. As development continues through the $21^{\text {st }}$ century, $\mathrm{CH}_{4}$ emissions due to heating of residential and commercial buildings using biomass become less significant than emissions by forest or grassland fire. 
Although significant changes in the relative contributions by the most significant sectors are projected under RCP 4.5, agriculture, energy, and waste continue to dominate in that order of importance as total emissions peak and then decline under the constraint to stabilize emissions at $4.5 \mathrm{~W} / \mathrm{m}^{2}$.

Figure 3.2.6 summarizes for each region and the world methane emissions associated with the six sectors of human activity responsible for most emissions. Agriculture is the dominant source of emissions by Asian, Latin American, and OECD 90 countries. In the Middle East and Africa, emissions associated with energy production and use and with agriculture have similar
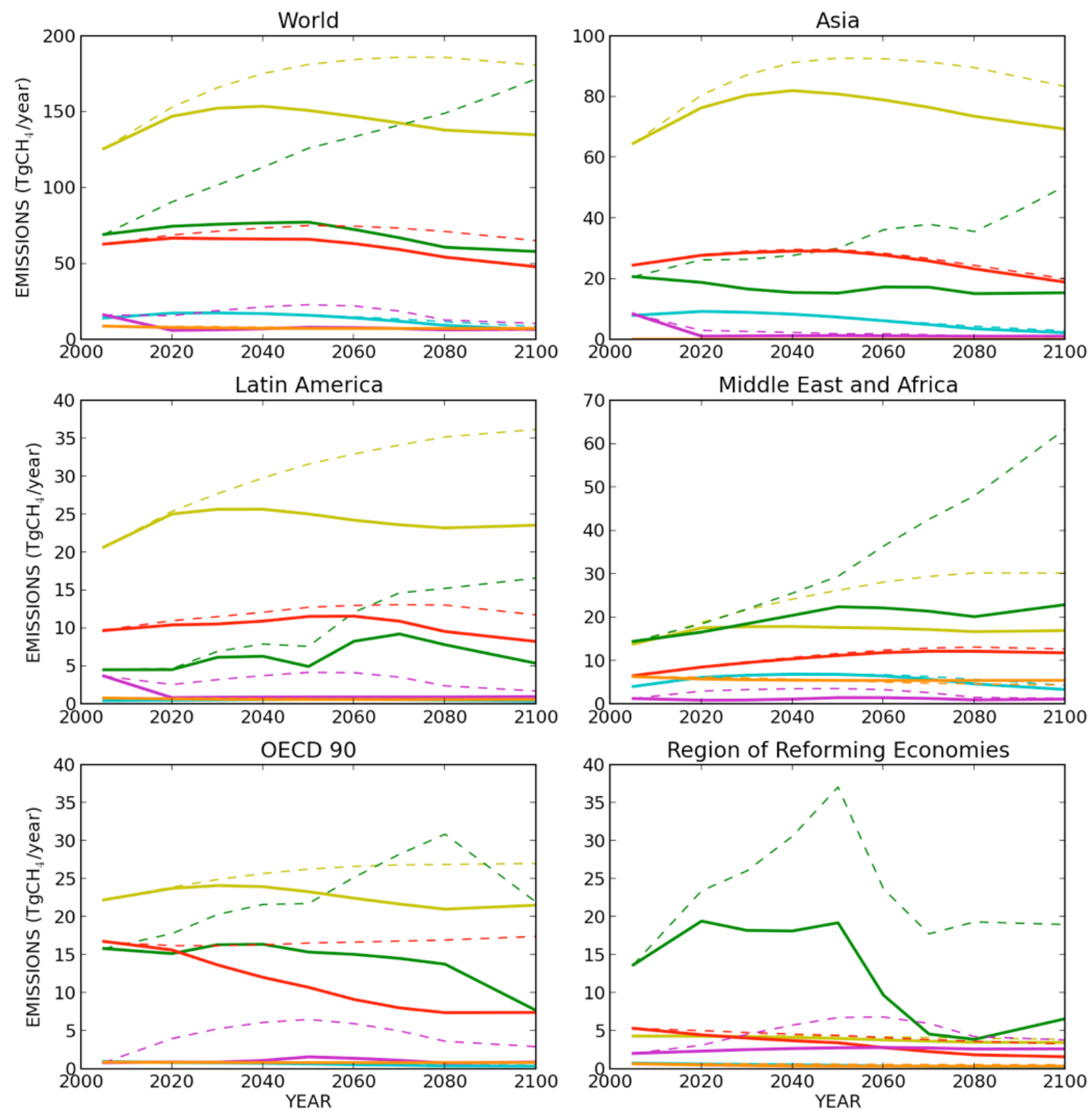

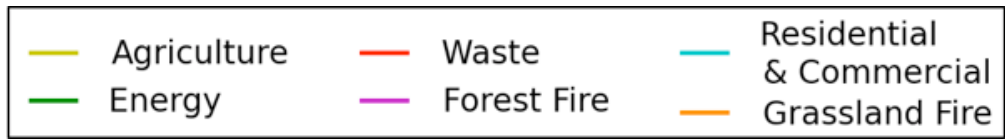

Figure 3.2.6. Methane emissions constrained by RCP 4.5 by major region and sector. Corresponding emissions in the reference scenario are displayed by dashed curves. 
magnitudes with energy overtaking agriculture after about year 2030. In the region of reforming economies, emissions associated with energy are significantly larger than those by other sectors until 2050, after which energy emissions fall sharply to levels similar to those by other sectors.

Agricultural emissions by countries in Asia and Latin America are responsible for the increase in total, global emissions under RCP 4.5 until about the year 2040. Emissions by energy production and use by countries within the region of reforming economies increase sharply until 2020 but their overall share in increasing total emissions are significantly less than that from agriculture. Emissions due to waste processing and storage by the OECD 90 countries diminish significantly through the century until about 2080 when they stabilize at a level about 50\% less than in 2010. Emissions associated with waste in Asia also decline after 2040 and in Latin America after 2060.

In many respects, the combination of increasing emissions by agriculture in Asia and Latin America until 2040 followed by declining emissions by both the agriculture and waste sectors in Asian, Latin American, and OECD 90 countries is responsible for the overall trend in total, global emissions. Decreases in energy related emissions by the OECD 90 countries are also significant as is the sharp decrease in energy emissions after 2050 by countries with reforming economies. These decreases offset increases due to energy production and use in Latin America, the Middle East, and Africa such that energy sector emissions are relatively constant globally.

The use of biomass to heat buildings is significant enough in Asia, the Middle East, and Africa to make this sector significant in total global emissions over most of the century. The steady decline in emissions by this sector within Asian countries makes them less significant than emissions by either forest or grassland fire by the end of the century.

\subsection{Geospatial Patterns in RCP 4.5 Emissions}

To enable the use of Representative Concentration Pathway emissions projections with atmospheric chemistry models, the IPCC scenario development team estimated spatial distributions of emissions based on expected correlations with population, land cover, agriculture, grazing, fire, and other attributes (van Vuuren et al., 2011; 2007). For RCP 4.5, emissions estimates for continental-scale regions were assigned to $0.5^{\circ}$ latitude $\times 0.5^{\circ}$ longitude land units consistent with geographic patterns in these underlying attributes. Downscaling emissions in this manner provides only a general approximation of their geospatial distributions; however, the patterns provide insights about geographic variations and potential changes through the $21^{\text {st }}$ century.

The map in Fig. 3.3.1 shows the distribution in year 2010 of total methane emissions by human activities across the Earth's landscape. Emissions are expressed as average fluxes over a year for each $0.5^{\circ}$ latitude $\times 0.5^{\circ}$ longitude geographic unit. Maximum emissions occur in India and Asia, particularly China. High emissions are also apparent across Europe and the United Kingdom. In some regions, for example the United States, Mexico, Brazil, and other parts of Latin America, average fluxes at intermediate levels extend over large land areas and are thus responsible for large emissions by the countries involved. 


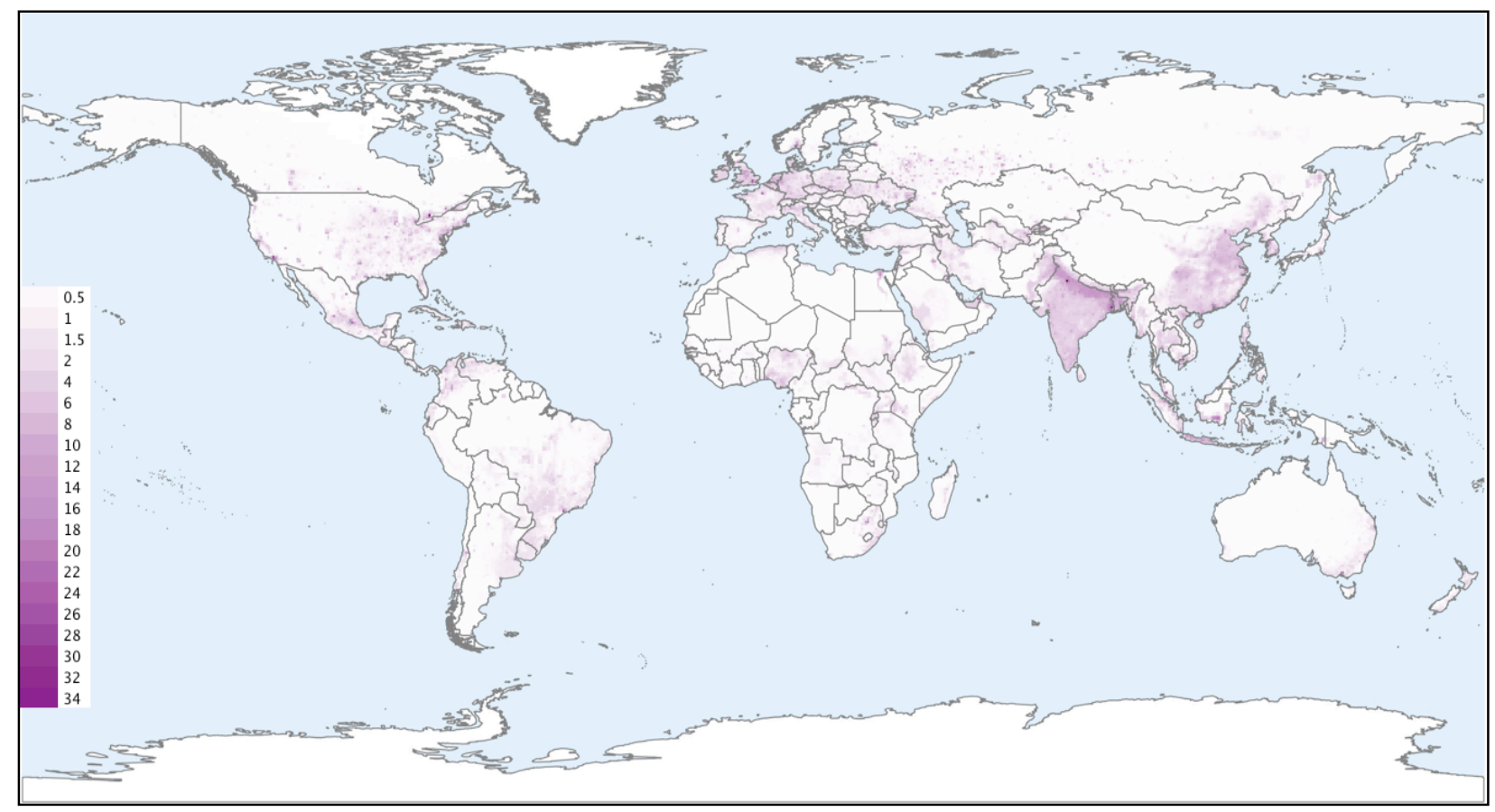

Figure 3.3.1. Geographic distribution of total $\mathrm{CH}_{4}$ emissions by human activities in 2010 under the RCP 4.5 scenario based on spatial correlations with underlying factors responsible for or aligned with emissions. Emissions are expressed as average fluxes $\left(\mathrm{kg}\left(\mathrm{CH}_{4}\right) / \mathrm{sec}\right)$ over a year for each $0.5^{\circ}$ latitude $\times 0.5^{\circ}$ longitude geographic unit.

Figure 3.3.2 shows the sector of human activity contributing the largest share to emissions from each $0.5^{\circ} \times 0.5^{\circ}$ geographic unit. It is important to recognize that the contributions by other sectors may be nearly as large as that by the dominant sector. Where agriculture is prevalent or population is sparse, agriculture tends to be responsible for the largest share of emissions.

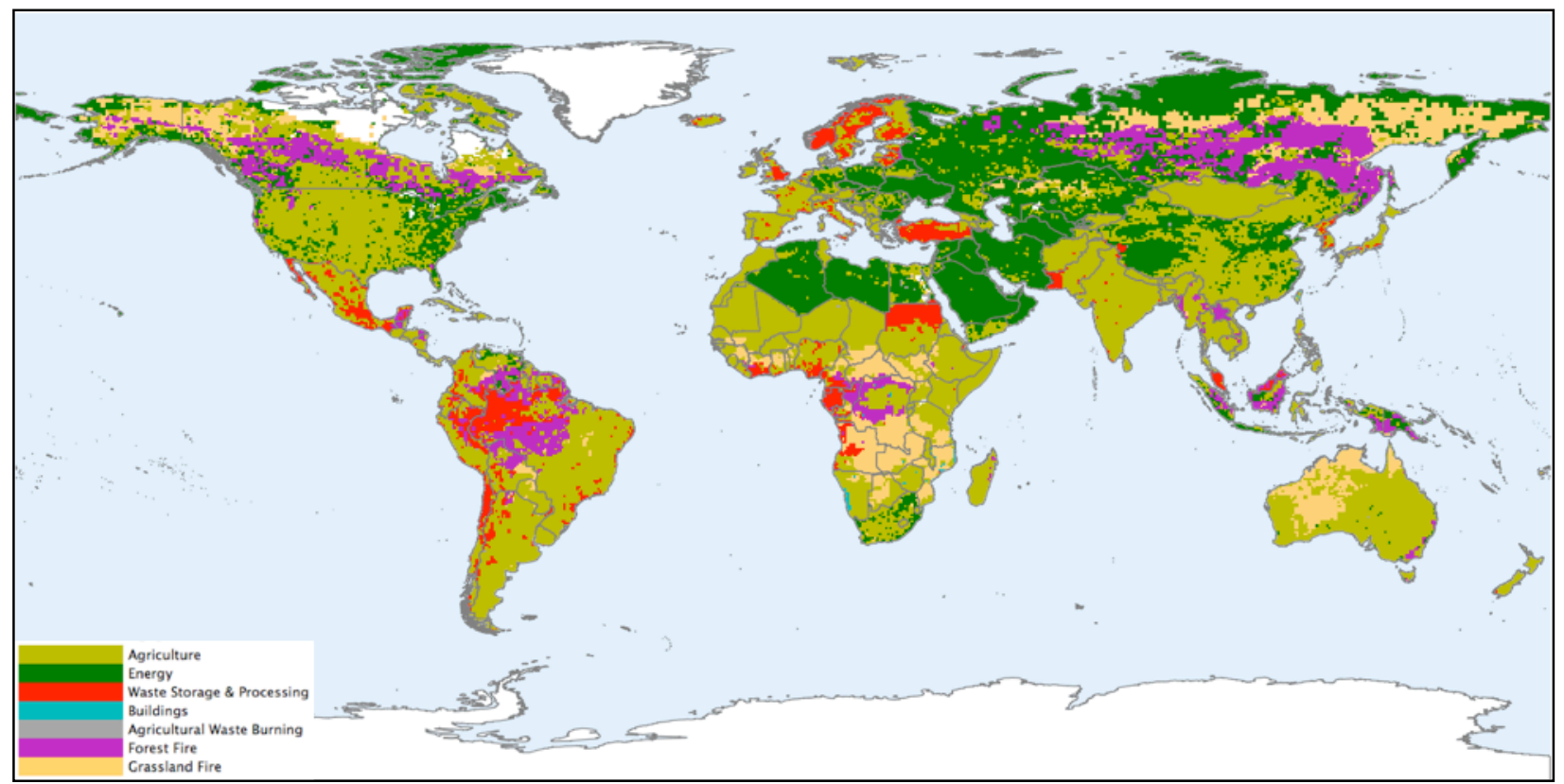

Figure 3.3.2. Sectors of human activity contributing most to methane emissions in 2010. The sector responsible for most emissions is identified for each geographic $0.5^{\circ} \times 0.5^{\circ}$ unit. Emissions by other sectors of activity may be significant or of nearly equal magnitude as emissions by the dominant sector. 


\section{Emissions Mitigation Implied by RCP 4.5}

Differences between reference scenario emissions, which are not constrained by climate relevant management or policies, and emissions constrained by RCP 4.5 represent the degree of mitigation in terms of reference scenario emissions that must be avoided as a function of time in order to stabilize radiative forcing at $4.5 \mathrm{~W} / \mathrm{m}^{2}$ instead of the significantly higher level associated with the reference scenario (Fig. 2.2.1).

For the six sectors responsible for the largest shares of total emissions, Fig. 4.1 displays the differences between reference scenario and RCP 4.5 emissions for each major region and for the world. By definition, emissions in 2010 are identical in the reference and RCP 4.5 scenarios. Beyond 2010, the difference indicates the amount of $\mathrm{CH}_{4}$ emissions in the reference scenario that must be avoided or offset in order to achieve the lower RCP 4.5 emissions. In these terms, the difference between reference scenario and RCP 4.5 emissions is greatest for countries in Asia, the Middle East, and Africa. With the exception of Latin America, differences in emissions associated with energy production and use are largest and represent the dominant difference in global emissions. 

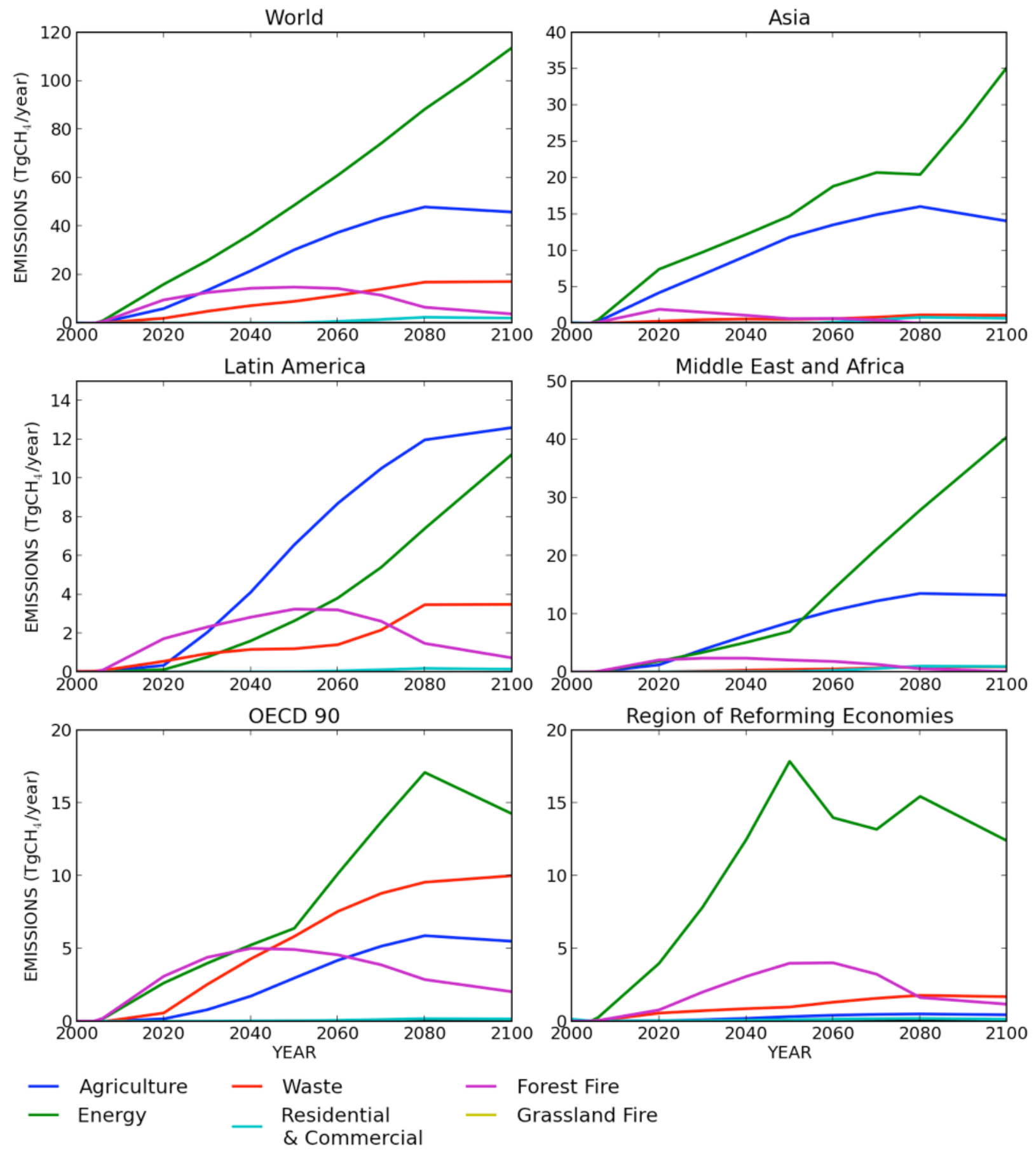

Figure 4.1. Differences by sectors and regions between reference scenario and RCP 4.5 emissions. Note that the scales of emissions axes differ between regions.

While agriculture dominates total methane emissions globally in both the reference and RCP 4.5 scenarios (Figs. 3.2.3 and 3.2.5), the largest emissions differences between these scenarios are associated with energy production and use. Globally, the magnitude of reference scenario emissions that must be avoided increases almost linearly to approximately $112 \mathrm{Tg}\left(\mathrm{CH}_{4}\right) / y$ ear in 
2100. This mitigation of emissions at year 2100 compares to total reference scenario emissions of about $450 \mathrm{Tg}\left(\mathrm{CH}_{4}\right) /$ year, or about $25 \%$ reduction from reference scenario emissions.

Although RCP 4.5 represents substantial mitigation of energy emissions in all regions, avoided emissions by Asian, Middle Eastern, and African countries are most significant. Consistent with patterns of expected development, the rate of increasing mitigation in the energy sector increases significantly after 2050. Trends and magnitudes of energy sector mitigation in countries of the OECD 90 and the region of reforming economies bear similarities. Both are at levels near $15 \mathrm{Tg}$ $\left(\mathrm{CH}_{4}\right) /$ year in 2100. But the region of reforming economies is assumed to increase mitigation in the energy sector much more rapidly than the OECD 90 countries, reaching a peak in 2050.

Only in Latin America does mitigation within the agricultural sector exceed that within the energy sector. But by the end of the century, both reach near $12 \mathrm{Tg}\left(\mathrm{CH}_{4}\right) /$ year. The trends in mitigation of agricultural emissions by other regions are similar and are evident in trends for global mitigation within this sector, increasing steadily until 2080 then stabilizing for the remainder of the century. With the exception of Asia, increases in mitigation of emissions due to agriculture are less significant prior to 2020. Agricultural emissions are not significant compared to other sectors in the degree of emissions mitigation RCP 4.5 assumes for the region of reforming economies.

In OECD 90 countries, mitigation of emissions associated with waste is larger throughout the $21^{\text {st }}$ century than for agricultural emissions. Avoiding reference scenario emissions from waste by OECD 90 as well as Latin American countries is responsible for most of the trend in mitigation of total emissions by this sector.

\section{Discussion and Conclusion}

The IPCC Representative Concentration Pathway to stabilize radiative forcing at $4.5 \mathrm{~W} / \mathrm{m}^{2}$ in year 2100 implies a substantial reduction of greenhouse gas emissions from reference scenario levels. Compared to the $40 \%$ increase in emissions that occurred since 1950, holding the maximum increase in $\mathrm{CH}_{4}$ emissions during this century to $10 \%$ and then instituting a steady decline in emissions after 2050 represents substantial mitigation.

The magnitude of reference scenario emissions that must be avoided annually in order to achieve the RCP 4.5 methane emissions pathway increases throughout the $21^{\text {st }}$ century to approximately $180 \mathrm{Tg}\left(\mathrm{CH}_{4}\right) /$ year in 2100 (Fig. 3.1). During year 2020, almost $10 \%$ of reference emissions must be mitigated, and during $2100,40 \%$ of reference emissions must be avoided. Over the course of the century, actions to achieve the RCP 4.5 pathway mitigate cumulative reference scenario emissions of $10,000 \mathrm{Tg}\left(\mathrm{CH}_{4}\right)$.

While under the RCP 4.5 scenario, Asian countries emit significantly more methane than do other regions (Fig. 3.1.1), through year 2050 the magnitudes of annual emissions that regions avoid in order to satisfy the RCP 4.5 constraint are more similar (Fig. 5.1 A). Emissions mitigation is largest for Asia, and the amount of methane emissions avoided each year by Asian countries increases sharply through year 2020. Annual emissions mitigation by countries in the Middle East and Africa also increase throughout the century, and overtake Asia during the last quarter of the century. 

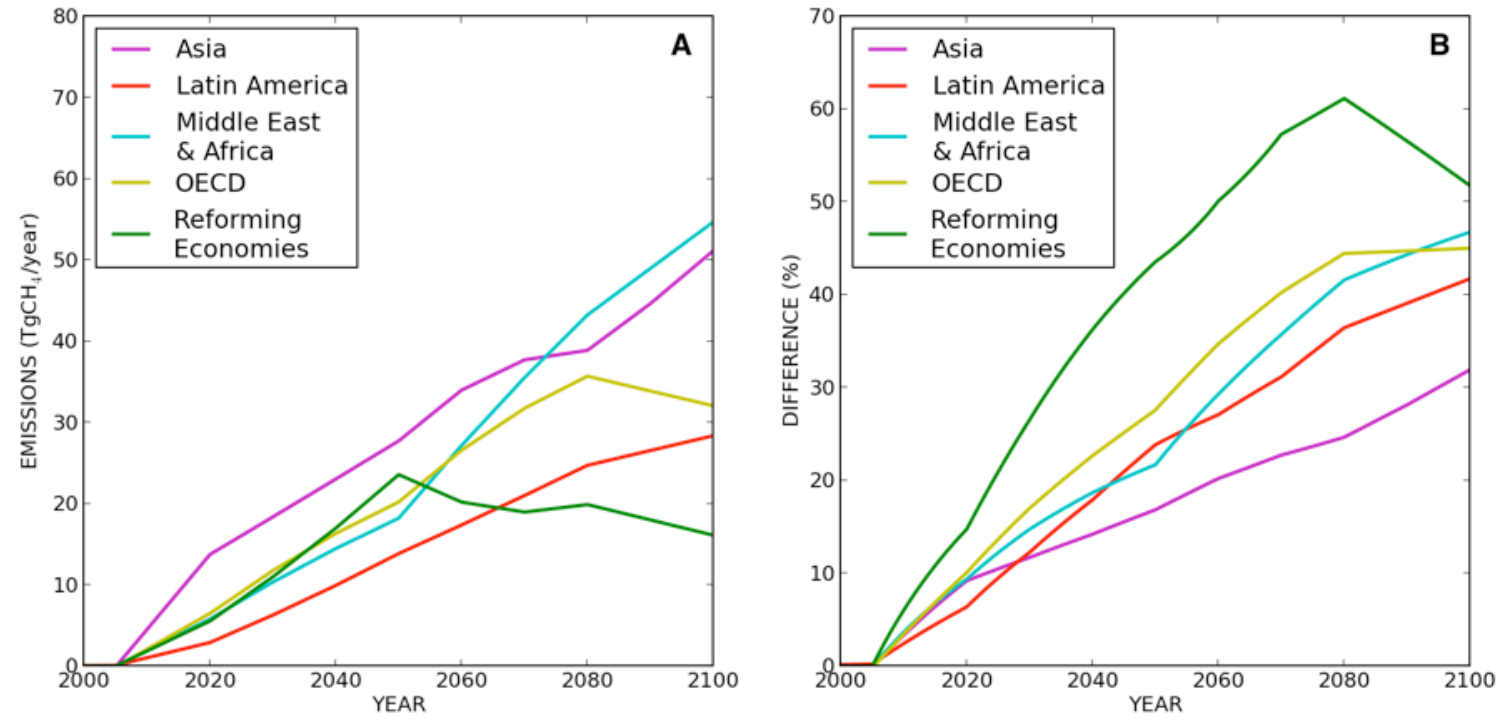

Figure 5.1. Difference between methane emissions in the reference and RCP 4.5 scenarios by region: (A) absolute difference in emissions; (B) difference in emissions relative to the reference scenario. The difference in emissions between the two scenarios corresponds to the mitigation of emissions annually required to achieve the RCP 4.5 pathway instead of that implied by the reference scenario.

The trends in emissions mitigation by the Middle East, Africa, the OECD 90 countries, and the region of reforming economies are similar through about 2050. Latin American countries avoid less annual emissions under RCP 4.5 and the amount increases more slowly. After 2050, annual mitigation of emissions by countries in the Middle East and Africa continues to increase; however, mitigation by countries in the region of reforming economies decreases. Mitigation within the OECD 90 countries increases at a steady rate until 2080 then declines.

The difference between annual methane emissions in the reference and RCP 4.5 scenarios relative to reference emissions provides a different measure of mitigation effort (Fig. 5.1 B). If the relative difference in emissions is high, then a region mitigates a large share of its reference scenario emissions. Relative mitigation is highest for the region of reforming economies and smallest for Asia, the region responsible for the largest share of absolute emissions. Other regions have more similar trends in their levels of relative mitigation under RCP 4.5. In 2080, countries in the region of reforming economies avoid over $60 \%$ of reference scenario emissions; maximum relative mitigation by any other region is approximately $46 \%$ in 2100 by the Middle East and Africa.

In the RCP 4.5 scenario, the OECD 90 countries are responsible for the second largest share of 2010 global emissions (Fig. 3.2.2). In 2100, the share of total, global emissions by the Middle East, Africa, and Latin America overtake those by the OECD 90. Although emissions by countries in the region of reforming economies represent the smallest fraction of total, global emissions throughout the century, this share decreases steadily from $9.3 \%$ in 2010 to $5.7 \%$ in 2100. By comparison, the shares in global emissions by the Middle East and Africa and by Latin America increase by $7.3 \%$ and $1.6 \%$ respectively. 
Methane emissions by agriculture, energy production and use, and by waste processing and storage are responsible for $87 \%$ of emissions in year 2010 (Fig. 3.2.4). The differences between reference scenario and RCP 4.5 emissions are far larger for the agriculture and energy sectors than for emissions associated with waste (Fig. 3.2.3). In RCP 4.5, emissions by the agriculture and energy sectors increase until about 2040 and then decline. In the reference scenario, emissions by agriculture increase until about 2060 then stabilize; energy sector emissions increase steadily throughout the century.

By far the largest emissions differences globally between the reference scenario and RCP 4.5 are associated with energy production and use (Fig. 4.1). In year 2100, the RCP 4.5 scenario avoids approximately $115 \mathrm{Tg}\left(\mathrm{CH}_{4}\right)$ /year in reference scenario emissions by the energy sector. This compares to about $300 \mathrm{Tg}\left(\mathrm{CH}_{4}\right) /$ year in 2010 total emissions globally. Mitigation of energy sector emissions to achieve RCP 4.5 is significant in all regions but largest in the Middle East, Africa, and Asia. Only in Latin America is mitigation associated with agriculture greater than that within the energy sector.

The near linear increase globally in the difference between reference scenario and RCP 4.5 emissions is supported by steadily increasing emissions mitigation in Asia, Latin America, the Middle East, and Africa. Mitigation of energy sector emissions decreases in the OECD 90 countries after 2080. In the region of reforming economies, mitigation of energy emissions increases until 2050 then declines. It is this pattern in mitigation of energy sector emissions that is most responsible for the significant increase in emissions mitigation on a relative basis by the region of reforming economies (Fig. 5.1).

Emissions mitigation associated with agriculture globally increases steadily until 2080 and then stabilizes (Fig. 4.1). This pattern is evident for each region as well, with mild decreases within Asia and the OECD 90 countries after 2080. In the OECD 90 countries, the annual mitigation of emissions associated with waste processing and storage is larger than that associated with agriculture. Mitigation of OECD 90 emissions by forest fire is also greater than that for waste or agriculture until forest fire reductions peak in 2040. Mitigation associated with forest fire is also significant in Latin America, reaching a peak in about 2050. In Latin America, mitigation of emissions associated with waste increases until 2080 then stabilizes. These patterns in mitigation of emissions by forest fire in regions other than Asia, the Middle East and Africa are responsible for similar patterns in global differences between annual reference scenario and RCP 4.5 emissions.

Methane emissions due to human activities are widespread across Earth's landscape (Fig. 3.4.1). This wide distribution of methane sources is in large part due to the major role of agriculture, including animal husbandry. Unlike $\mathrm{CO}_{2}$ emissions from power plants, industrial facilities, and along transportation corridors, $\mathrm{CH}_{4}$ emissions associated with energy production and use are more distributed geographically, particularly where natural gas releases from pipelines, with extraction, or by incomplete flaring are involved. In Fig. 3.4.1, areas where agriculture, particularly rice production, grazing, and similar activities as well as energy production occur are particularly prevalent. But although at the resolution of $0.5^{\circ} \times 0.5^{\circ}$ geographic units $(\sim 50 \mathrm{~km} \times$ $50 \mathrm{~km}$ at the equator), methane emissions may be small, the total over large areas can be substantial. Thus, where low-level emissions are spread over large areas, small decreases can be 
significant at country and regional scales. At the same time, such low-level mitigation over large areas may be difficult to implement.

\section{Literature Cited}

Anderson, B., K. Bartlett, S. Frolking, K. Kayhoe, J. Jenkins, and W. Salas. 2010. Methane and Nitrous Oxide Emissions from Natural Sources. EPA 430-R-10-001, Office of Atmospheric Programs, U.S. Environmental Protection Agency, Washington, D.C.

Clarke, L., J. Edmonds, J. Jacoby, H. Pitcher, J. Reilly, R. Richels, E. Parson, V. Burkett, K. Fisher-Vanden, D. Keith, L. Mearns, C. Rosenzweig, and M. Webster. 2007. Scenarios of Greenhouse Gas Emissions and Atmospheric Concentrations. U.S. Department of Energy, Washington, DC.

Denman, K. L., G. Brasseur, A. Chidthaisong, P. Ciais, P. M. Cox, R. E. Dickinson, D. Hauglustaine, C. Heinze, E. Holland, D. Jacob, U. Lohmann, S. Ramachandran, P. L. da Silva Dias, S. C. Wofsy, and X. Zhang. 2007. Couplings between changes in the climate system and biogeochemistry.in S. Solomon, D. Qin, M. Manning, Z. Chen, M. Marquis, K. B. Averyt, M. Tignor, and H. L. Miller, editors. Climate Change 2007: The Physical Science Basis. Contribution of Working Group I to the Fourth Assessment Report of the Intergovernmental Panel on Climate Change. Cambridge University Press, Cambridge, U.K.

Dlugokencky, E. J., E. G. Nisbet, R. Fisher, and D. Lowry. 2011. Global atmospheric methane: Budget, changes and dangers. Philosophical Transactions of the Royal Society A 369:20582072.

Etheridge, D. M., L. P. Steele, R. J. Francey, and R. L. Langenfelds. 1998. Atmospheric methane between 1000 A.D. and present: Evidence of Anthropogenic emissions and climatic variability. Journal of Geophysical Research 103:15979-15996.

Forster, P., V. Ramaswamy, P. Artaxo, T. Berntsen, R. Betts, D. W. Fahey, J. Haywood, J. Lean, D. C. Lowe, G. Myhre, J. Nganga, R. Prinn, G. Raga, M. Schulz, and R. Van Dorland. 2007. Changes in Atmospheric Constituents and in Radiative Forcing. Pages 129-234 in S. Solomon, D. Qin, M. Manning, Z. Chen, M. Marquis, K. B. Averyt, M. Tignor, and H. L. Miller, editors. Climate Change 2007: The Physical Basis. Cambridge University Press, Cambridge, U.K.

Khalil, M. A. K., and R. A. Rasmussen. 1994. Global emissions of methane during the last several centuries. Chemosphere 29:833-842.

Moss, R. H., J. A. Edmonds, K. A. Hibbard, M. R. Manning, S. K. Rose, D. P. van Vuuren, T. R. Carter, S. Emori, M. Kainuma, K. T., G. A. Meehl, J. F. B. Mitchell, N. Nakicenovic, K. Riahi, S. J. Smith, R. J. Stouffer, A. M. Thomson, J. P. Weyant, and T. J. Wilbanks. 2010. The next generation of scenarios for climate change research and assessment. Nature 463:747-756.

Nakicenovic, N. and R. Swart, editors. 2000. Special Report on Emissions Scenarios. Cambridge University Press, Cambridge, U.K. 
O’Neill, B. C. 2005. Population scenarios based on probabilistic projections: An application for the Millennium Ecosystem Assessment. Population and Environment 26:229-254.

Peters, G. P., R. M. Andrew, T. Boden, J. G. Canadell, P. Ciais, C. Le Quere, G. Marland, M. R. Raupach, and C. Wilson. 2013. The challenge to keep global warming below $2^{\circ}$ C. Nature Climate Change 3:4-6.

Prather, M. J., C. C. Holmes, and J. Hsu. 2012. Reactive greenhouse gas scenarios: Systematic exploration of uncertainties and the role of atmospheric chemistry. Geophysical Research Letters 39:L09803.

Scheehle, E. A. and D. Kruger. 2006. Global anthropogenic methane and nitrous oxide emissions. The Energy Journal Special Issue:33-44.

Smith, S. J. and T. M. L. Wigley. 2006. Multi-Gas forcing stabilization with Minicam. The Energy Journal Supplement:373-391.

Thomson, A. M., K. V. Calvin, S. J. Smith, G. P. Kyle, A. Volke, P. Patel, S. Delgado-Arias, B. Bond-Lamberty, M. A. Wise, L. E. Clarke, and J. A. Edmonds. 2011. RCP4.5: A pathway for stabilization of radiative forcing by 2100. Climatic Change 109:77-94.

Thomson, A. M., K. V. Calvin, L. P. Chini, G. Hurtt, J. A. Edmonds, B. Bond-Lamberty, S. Frolking, M. A. Wise, and A. C. Janetos. 2010. Climate mitigation and the future of tropical landscapes. Proceedings of the National Academy of Sciences of the United States of America 107:19633-19638.

UN. 2006. World Population Prospects: The 2004 Revision. United Nations, New York, New York.

van Vuuren, D., J. Edmonds, M. Kainuma, K. Riahi, A. Thomson, K. Hibbard, G. Hurtt, T. Kram, V. Krey, J.-F. Lamarque, T. Masui, M. Meinshausen, N. Nakicenovic, S. Smith, and S. Rose. 2011. The representative concentration pathways: An overview. Climatic Change 109:5-31.

van Vuuren, D. P., P. L. Lucas, and H. Hilderink. 2007. Downscaling drivers of global environmental change: Enabling use of global SRES scenarios at the national and grid levels. Global Environmental Change 17:114-130.

Wise, M., K. V. Calvin, A. M. Thomson, L. E. Clarke, B. Bond-Lamberty, R. D. Sands, S. J. Smith, A. C. Janetos, and J. A. Edmonds. 2009. The implications of limiting $\mathrm{CO}_{2}$ concentrations for land use and energy. Science 324:1183-1186.

Wuebbles, D. J., and K. Hayhoe. 2002. Atmospheric methane and global change. Earth-Science Reviews 57:177-210. 


\section{Appendix A - RCP Region Definitions}

\section{Organization for Economic Cooperation and Development 90 (OECD90)}

Western Europe, North America, and Pacific OECD Nations

Austria, Belgium, Denmark, Finland, France, Germany, Greece, Iceland, Ireland, Italy, Luxembourg, Netherlands, Norway, Portugal, Spain, Sweden, Switzerland, Turkey, United Kingdom, Canada, United States of America, Australia, Fiji, French Polynesia, Guam, Japan, New Caledonia, New Zealand, Samoa, Solomon Islands, and Vanuatu.

\section{Reforming Economies (REF)}

Albania, Armenia, Azerbaijan, Belarus, Bosnia and Herzegovina, Bulgaria, Croatia, Cyprus, Czech Republic, Estonia, Georgia, Hungary, Kazakhstan, Kyrgyzstan, Latvia, Lithuania, Malta, Poland, Republic of Moldova, Romania, Russian Federation, Slovakia, Slovenia, Tajikistan, The Former Yugoslav Republic of Macedonia, Turkmenistan, Ukraine, Uzbekistan, and Yugoslavia.

\section{Asia}

China, India, and Other Nations of Asia

China, Hong Kong Special Administrative Region of China, Macao Special Administrative Region of China, Mongolia, Taiwan, Afghanistan, Bangladesh, Bhutan, India, Maldives, Nepal, Pakistan, Sri Lanka, Brunei Darussalam, Cambodia, Democratic People's Republic of Korea, East Timor, Indonesia, Lao People's Democratic Republic, Malaysia, Myanmar, Papua New Guinea, Philippines, Republic of Korea, Singapore, Thailand, Viet Nam.

\section{Middle East and Africa (MAF)}

Bahrain, Islamic Republic of Iran, Iraq, Israel, Jordan, Kuwait, Lebanon, Oman, Qatar, Saudi Arabia, Syrian Arab Republic, United Arab Emirates, Yemen, Algeria, Angola, Benin, Botswana, Burkina Faso, Burundi, Cote d'Ivoire, Cameroon, Cape Verde, Central African Republic, Chad, Comoros, Congo, Democratic Republic of the Congo, Djibouti, Egypt, Equatorial Guinea, Eritrea, Ethiopia, Gabon, Gambia, Ghana, Guinea, Guinea-Bissau, Kenya, Lesotho, Liberia, Libyan Arab Jamahiriya, Madagascar, Malawi, Mali, Mauritania, Mauritius, Morocco, Mozambique, Namibia, Niger, Nigeria, Reunion, Rwanda, Senegal, Sierra Leone, Somalia, South Africa, Sudan, Swaziland, Togo, Tunisia, Uganda, United Republic of Tanzania, Western Sahara, Zambia, Zimbabwe.

\section{Latin America (LAM)}

Argentina, Bahamas, Barbados, Belize, Bolivia, Brazil, Chile, Colombia, Costa Rica, Cuba, Dominican Republic, Ecuador, El Salvador, Guadeloupe, Guatemala, Guyana, Haiti, Honduras, Jamaica, Martinique, Mexico, Netherlands Antilles, Nicaragua, Panama, Paraguay, Peru, Puerto Rico, Suriname, Trinidad and Tobago, Uruguay, and Venezuela. 